\title{
LA ASOCIACIÓN CATÓLICA NACIONAL DE PROPAGANDISTAS DURANTE LA FASE CENTRAL DEL RÉGIMEN DE FRANCO
}

POR

\author{
Antonio Martín Puerta
}

Universidad San Pablo CEU, Madrid

\begin{abstract}
RESUMEN
La creación de la ACN de P en 1909 responde a la necesidad de generar una forma actualizada de presencia pública del catolicismo. Durante el régimen de Franco la ACN de P tuvo una importante repercusión en la vida pública: influyó en los ámbitos institucionales; sus miembros colaboraron en la vida de las organizaciones católicas; también en obras asistenciales, dada la complicada situación social de la época. Hacia la mitad del régimen se generan varios puntos de inflexión histórica: un nuevo gobierno en 1957; la constitución del Mercado Común; la política de estabilización, que modifica el modelo económico; finalmente, el Concilio Vaticano II. Todas estas líneas modifican el panorama de fondo. Los propagandistas también modificarán sus actuaciones en la vida política y religiosa, en consonancia con tales cambios.
\end{abstract}

Palabras ClaVE: Vida pública. Influencia institucional. Estado confesional. Doctrina Social de la Iglesia. Evolución política. Promoción de la participación. Desarrollo político.

\section{THE ACN DE P DURING THE CENTRAL PHASE FRANCO'S REGIME}

\begin{abstract}
The creation of the ACN de $\mathrm{P}$ in 1909 is the result of a need: to try to develop a modern form of public action for the Catholicism. Inside the Franco's political system, the ACN de P had important influence in the political life: institutional influence. The members of the association developed an important role inside catholic and social institutions. Important new events during the central years of the system where going to be definitive. A new government in 1957; the creation of the Common Market; the new economic policy; and finally, the Vatican
\end{abstract}


Council. All these lines were going to modify the background. The members of ACN de P will change their lines of action too.

KeY WORDS: Public life. Institutional influence. Confessionalism. Social Doctrine of the Church. Political evolution. Action in favor of political participation. Political development.

\author{
Recibido/Received 30-07-2011 \\ Aceptado/Accepted [03-09-2014
}

La Asociación Católica Nacional de Propagandistas, fundada en 1909 por un jesuita, Don Ángel Ayala, ha sobrepasado recientemente cien años de presencia en la vida pública y religiosa de nuestro país. Para cualquier conocedor de la historia contemporánea de España es evidente su relieve desde el punto de vista religioso, político, social y de influencia en los medios de comunicación. Ello debido a la impronta infundida por una personalidad nada común: Ángel Herrera, un abogado del Estado que la acaudilló desde sus orígenes hasta 1935, para luego profesar como sacerdote, ser nombrado obispo de Málaga en junio de 1947 y cardenal de la Iglesia en febrero de 1965. Es y ha sido la Asociación de Propagandistas una entidad peculiar, de la que uno de sus presidentes, Francisco Guijarro, decía que resultaba muy difícil comprender desde fuera. En efecto, así ha sido desde el principio, aunque las claves para su interpretación no son nada complejas, ni tampoco le es atribuible una vocación por lo secreto; bien al revés: pocas entidades, religiosas o no, han dejado plasmadas de modo tan evidente en las páginas de sus boletines las distintas interpretaciones que sus socios tenían acerca de cuestiones capitales. Lo que la hace peculiar es la romanidad de su origen, su especial subordinación a los criterios de la jerarquía de la Iglesia, la voluntad de acatamiento a los poderes constituidos y la búsqueda de la proyección social del catolicismo. Proyección que se ha efectuado a través de obras creadas específicamente para ciertos fines, y cuyo historial incluye también un elemento que causa sorpresa: ¿cómo una asociación que nominalmente ha tenido una media histórica de no más de seiscientos socios -siendo efectivos no más de la mitad a efectos de actuación- ha podido alcanzar tal relevancia en la historia de España?

\title{
EL TRASFONDO HISTÓRICO DE SU CREACIÓN
}

Para conocer las razones históricas de la creación de la ACN de P no puede prescindirse -ya se ha mencionado el elemento de romanidad- de cuáles eran los elementos de juicio que en Roma prevalecían en cuanto a las formas de actuación de los católicos en la vida pública en los países clave. Hablamos de Francia y de Alemania, países centrales entonces y hoy, cuyos movimientos católicos habían actuado de modo completamente opuesto, y con resultados también distintos. 
Proclamada la III República en 1870, y habiendo cobrado esta desde 1880 un fuerte sesgo anticatólico, el modelo francés fue el de un predominante catolicismo reactivo, vinculado al legitimismo y a posturas de carácter integrista. El resultado fue calamitoso: en 1905 se consumaba con la Ley de Separación de las Iglesias y el Estado un sistema que había acabado por segregar socialmente a la Iglesia. El modelo alemán, por el contrario, se basó en la difícil inserción de los católicos dentro de las estructuras de un Imperio proclamado en 1871, con carácter fuertemente luterano y con la impronta anticatólica del Kulturkampf. Pocos años más tarde, y con el instrumento fundamental del Zentrum Partei, se había logrado erradicar los elementos esenciales del anticatolicismo, siendo elemento determinante, además, para el establecimiento de la política social más avanzada de Europa. Dos modelos bien distintos tanto en planteamiento como en resultados. De lo que Roma era perfectamente consciente. Ahora bien: ¿qué expectativas ofrecía España? Evidentemente, las de seguimiento de la vía francesa. ${ }^{1}$ Había para ello un elemento notoriamente influyente: el integrismo, siempre exaltador de una visión hispánica lindante con la xenofobia, pero con frecuencia, en la realidad, imitando e inspirándose en los integristas y legitimistas franceses. Maximiliano Arboleya y Juan María Laboa han analizado con detalle los efectos de la trayectoria integrista. ${ }^{2}$

Pero en España la política antirreligiosa francesa había empezado a tener sus imitadores. Para empezar con actitudes reticentes de los gobiernos liberales en materia educativa, y con una pública actitud contra la expansión de la Iglesia con la llamada «Ley del Candado» de 28 de diciembre de 1910, siendo Canalejas presidente del Consejo de Ministros. El nacimiento en 1909 de la ACN de P obedeció a la preocupación romana por las cosas de España. Existía el temor de que, con toda posibilidad, se seguiría el camino del catolicismo francés. Y se buscó desarrollar un planteamiento estratégico que ya había tenido su implantación en Alemania a través del Zentrum y del catolicismo social. Muestra significativa de ello es el siguiente dato: en 1883 el presidente de la Comisión de estudios sociales del Zentrum, el príncipe de Loewenstein, escribía estas palabras acerca de una república que algunos pocos veían en el horizonte: «nosotros podemos convertirnos en sus dueños». ${ }^{3}$ Tal hecho tendría lugar en 1918, treinta y seis años después; el Zentrum pasó a ser elemento clave de la República, y sus sucesores siguen hoy gobernando en Alemania. El hombre que en España desarrollaría una estrategia

\footnotetext{
${ }^{1}$ Sobre la preocupación del cardenal Secretario de Estado, Merry del Val, por una reproducción en España del modelo laicista francés ver Larkin, M. 2004. L'Église et l'État en France. 1905: La crise de la séparation: 198-200 Paris: Privat. Otro tanto se observa en la carta del obispo de Niza, monseñor Chapon, remitida al P. Lecanuet el 20 de mayo de 1910. Ver Lecanuet, É. 1910. L'Église de France sous la Troisième République (1878-1894): XI París: Ancienne Librairie Poussielgue.

${ }^{2}$ Ver Arboleya, M. 1930. Otra Masonería. El integrismo: Madrid: Cía. Ibero-Americana de Publicaciones. Y Laboa, J.M. 1985. El integrismo, un talante limitado y excluyente: Madrid: Narcea.

${ }^{3}$ Rovan, J. 1964. El catolicismo político en Alemania: 158 Madrid: Instituto de Estudios Políticos.
} 
comparable sería el sucesor del P. Ayala: Ángel Herrera Oria. Por encima de cuáles pudieran ser los regímenes políticos, y a través de las obras creadas para la proyección del catolicismo en la sociedad, la Asociación Católica de Propagandistas lleva cien años de actividad, en general no demasiado conocida -al contrario que sus obras-ni siempre bien comprendida, ello desde los propios orígenes. ${ }^{4}$

\section{LA ACN DE P y EL NUEVo RÉGIMEN DE 1939}

Era evidente que no faltaban en el nuevo régimen quienes se situaban frente a la Asociación, lo que fundamentalmente ocurrió por hostilidad política. Una de las obras creadas por Herrera fue Acción Nacional -pronto Acción Popular, ante la prohibición de Azaña de utilizar el término «nacional» salvo por organismos oficiales-, que sería el núcleo de la CEDA. La no fácil recuperación de $E l$ Debate, cuya publicación no se autorizó alegando que en Madrid existía el diario $Y a$-un mismo grupo no podía publicar dos diarios en la misma ciudad- fue ejemplo de ello. Pero Ya tendría hasta 1952 un director impuesto por Serrano Súñer, Juan José Pradera, situación bien expresiva de las reticencias hacia la Asociación, pese a haber en ese momento en el gobierno dos ministros propagandistas. No son infrecuentes por esas fechas las alusiones en los órganos del Movimiento contra la democracia cristiana, identificación, cuando menos por esas fechas, no particularmente exacta. De hecho la asociación como tal no ha tenido rango político, y estuvo presidida hasta 1953 por Fernando Martín Sánchez Juliá, nada dudoso partidario del régimen. Por otro lado la mayoría de los socios era partidaria del sistema, aunque, también mayoritariamente, favorable a su evolución y a la eliminación de cualquier formato de inspiración totalitaria. No faltando tampoco nunca un sector de oposición, que desde 1954 se vincularía a la Asociación Española para la Cooperación con Europa, orientado hacia posiciones demócrata cristianas, y generalmente conexas con la línea de Don Juan de Borbón.

La completa rehabilitación de la Asociación para la vida pública vino de la mano de la complicada situación de España a partir del final de la Segunda Guerra Mundial. Las previas y especiales relaciones del sistema político con los países derrotados habían creado la imagen de un régimen anómalo dentro del nuevo orden mundial. En buena parte la identificación del sistema con los modelos totalitarios era incorrecta, más allá de las apariencias externas. De hecho Falange nunca tuvo control sobre los ministerios esenciales, Ejército,

\footnotetext{
${ }^{4}$ De hecho el cardenal arzobispo de Madrid, don José María Salvador y Barrera, manifestó, ya en los primeros momentos, reservas ante la nueva agrupación, creada, decía, «sin anuencia mía». El personaje crucial en la creación había sido el nuncio, Monseñor Antonio Vico. Sobre el desarrollo inicial ver Gutiérrez García, J.L. 2010. Historia de la Asociación Católica de Propagandistas. (1908-1923): Madrid: CEU Ediciones.
} 
Hacienda, o Gobernación, salvado para este último caso la presencia de Serrano Súñer desde 1938 hasta octubre de 1940. Incluso para muchos falangistas, llamar «nacionalsindicalismo» a un sistema en el que no había sino uno o dos ministros falangistas, salvo el titular de la Secretaría General del Movimiento -que ni siquiera controlaba más que una de las cuatro fuerzas originarias del Movimiento-, aparecía como absurdo. Pero, ciertamente, la imagen ofrecida por el régimen, tenía vinculaciones provenientes de la guerra civil, ribetes y estética de carácter totalitario. No había otra salida que la utilización de políticos católicos que modificaran la imagen exterior del sistema, de modo que el anterior ministro de Asuntos Exteriores, José Félix de Lequerica, fue sustituido por Alberto Martín Artajo, hasta la fecha Presidente de la Junta Técnica de Acción Católica. Franco transmitió este requerimiento a Carrero Blanco: «Necesito un católico»; el designado solicitaría la autorización previa del primado Pla y Deniel, que le alentaría para aceptar tal propuesta. ${ }^{5}$ Aunque ciertamente el más notable, no era el único propagandista que ocupaba puestos en los gobiernos nombrados tras la guerra. José Ibáñez Martín sería ministro de Educación Nacional desde agosto de 1939 hasta julio de 1951; José Larraz sería nombrado ministro de Hacienda también en 1939, como igualmente, dato poco conocido, el Ministro sin Cartera, Pedro Gamero del Castillo, antes Vicesecretario General del Partido, era igualmente un hombre proveniente de la Asociación. Como también José María Fernández Ladreda, titular de Obras Públicas entre 1945 y 1951.

Era evidente, en cualquier caso, el carácter católico del régimen, con un catolicismo recién salido de una persecución y de una guerra civil, lo que le daba matices históricos peculiares. La carta pastoral del primado, cardenal Gomá, Catolicismo y Patria, de 5 de febrero de 1939 definía ese estadio histórico: «Catolicismo y Patriotismo representan para nosotros a un tiempo los factores máximos de nuestra grandeza y el doble altar en que ofrezcamos los mayores sacrificios». Pero, alertando contra las concepciones totalitarias, advertía: «Es a veces la exageración, la sustancialización, hasta la divinización del Estado, que transforman los fines del poder político, haciendo de él fin supremo de las actividades del hombre, que queda absorbido por la fuerza estatal que lo invade todo». Pronto sería la Iglesia el principal freno contra las tendencias totalitarias, y uno de sus principales instrumentos de acción, en cumplimiento de sus objetivos de origen, la ACN de P.

\section{EL ENTORNO DE LA ÉPOCA}

El espacio histórico que tratamos ha venido a quedar caracterizado por un conjunto de lugares comunes poco conexos con la realidad en muchos casos. Es

${ }^{5}$ Marquina Barrio, A. 1983. La diplomacia vaticana y la España de Franco: 330 Madrid: CSIC. 
una etapa sobre la que los historiadores tienen todavía mucho que decir. Que aún se dejaban sentir los efectos de la posguerra es evidente. Que es una época de floreciente recuperación del catolicismo, es también obvio: no sólo por la anulación de la legislación laicista de la República, sino por un intenso trabajo de la Iglesia, que logra impregnar notablemente la sociedad del momento. Ahora bien, el subsuelo abarca unas corrientes no siempre reconocidas que terminarán aflorando para sorpresa de muchos. Pues resulta que la sociedad oficialmente cristiana regida por un estado confesional, es, en muchos casos, sólo nominalmente cristiana. Bastantes organismos sociales creados para la acción de la Iglesia, si bien se encuentran nutridos en número, empezarán, ya en los años cincuenta, a manifestar ciertos rasgos de languidez y de crisis. Los seminarios, expandidos en dimensiones sin precedentes durante esos años, empezarán a reflejar poco a poco una caída de vocaciones que, dato importante, es anterior al Concilio. Y el ambiente socioeconómico seguirá siendo, hasta principios de los años sesenta, reflejo de un país que acumula serias lacras históricas. Aspectos todos que condicionan seriamente la actividad pública de cualquier entidad de tipo apostólico. El llamado «nacionalcatolicismo», un concepto de no fácil acotación, aunque expresivo de una época de estrecha vinculación de la Iglesia y el Estado, encierra más sorpresas de las que se piensa. Ni fue una etapa tan obscura y gris como con frecuencia se quiere presentar, ni las relaciones entre el Estado y la Iglesia carecían de suspicacias, ni tampoco la sociedad era tan católica como se supone. Prueba de lo dicho es el número de sacerdotes por persona dedicado a labores parroquiales en 1959; resulta que España aparece en el tercer puesto por la cola, sorprendentemente acompañado por los países considerados como más católicos, tal como Stanley Payne refleja en su libro El catolicismo español :

\begin{tabular}{|c|c|}
\hline País & Habitantes/sacerdote parroquial \\
\hline Suiza & 766 \\
\hline Holanda & 907 \\
\hline Irlanda & 917 \\
\hline Bélgica & 974 \\
\hline Francia & 1.090 \\
\hline Italia & 1.109 \\
\hline Alemania & 1.125 \\
\hline ESPÃ̃) & $\mathbf{1 . 3 3 6}$ \\
\hline Austria & 1.578 \\
\hline Portugal & 2.311 \\
\hline
\end{tabular}


Como es digna de considerar la tabla ofrecida por Guy Hermet acerca de la evolución de la senda de seminaristas: ${ }^{6}$

\begin{tabular}{|c|c|c|c|c|c|}
\hline Año & Inscritos & Abandonos & Año & Inscritos & Abandonos \\
\hline $1953-1954$ & 8.406 & 446 & $1963-1964$ & 8.021 & 888 \\
\hline $1954-1955$ & 8.301 & 530 & $1964-1965$ & 7.903 & 978 \\
\hline $1955-1956$ & 8.242 & 554 & $1965-1966$ & 7.689 & 1.147 \\
\hline $1956-1957$ & 8.230 & 561 & $1966-1967$ & 7.114 & 1.719 \\
\hline $1957-1958$ & 8.470 & 638 & $1967-1968$ & 5.945 & 1.563 \\
\hline $1958-1959$ & 8.511 & 765 & $1968-1969$ & 4.823 & 1.465 \\
\hline $1959-1960$ & 8.728 & 740 & $1969-1970$ & 3.932 & 1.161 \\
\hline $1960-1961$ & 8.610 & 760 & $1970-1971$ & 3.526 & \\
\hline $1961-1962$ & 8.397 & 782 & $1971-1972$ & 3.014 & \\
\hline $1962-1963$ & 8.340 & 841 & & & \\
\hline
\end{tabular}

Por no hablar de la evolución de las afiliaciones a Acción Católica, sobre lo que explica José Andrés Gallego: «...habían sido casi 600.000 en 1955; eran 500.000 en 1966, de los que en 1979 quedarían -conocidos- menos de 15.000. Decimos conocidos porque la pluralidad de los movimientos de $\mathrm{AC}$, la propia naturaleza - tan diversa- de la adscripción a los mismos y las meras deficiencias de la estadística interna hacen que esas cifras no sean más que estimaciones seguramente aproximadas de la realidad. La JOC (Juventud Obrera Católica) pasa de 87.000 al comenzar la década de los sesenta a ochocientos en 1979; las mujeres de AC, de 150.000 a 11.000. No pocos dejan también la Iglesia y pierden la fe». ${ }^{7}$ Declive de Acción Católica que causaba verdadera preocupación en la Nunciatura ya en $1957 .{ }^{8}$ En cuanto a la situación social, hoy olvidada en un

${ }^{6}$ Hermet, G. 1980. Les catholiques dans l'Espagne franquiste: 46-48 Paris: Presses de la Fondation Nationale de Sciences Politiques.

${ }^{7}$ Andrés Gallego, J. 1992. «Entre la religión y la política», en Andrés Gallego (coord.), Historia general de España y América: T. XIX-1,136-137 Madrid: RIALP.

${ }^{8}$ Revelador de ello es el contenido de una nota que aparece en el archivo de Castiella. A lo largo de una conversación sostenida por D. Esteban Fernández Ruiz con el Nuncio y con el Auditor de la Nunciatura, Monseñor Carlo Martini, éste efectuó unos reveladores comentarios sobre algunos aspectos de la situación religiosa de la España de los años cincuenta. Observa sobre las Conferencias de Metropolitanos: «El temario de las conferencias es de llorar. Asuntos de escaso interés cuyos acuerdos, 
país pobre hasta hace no mucho, por aquellas fechas era de verdadera acumulación de dificultades.

Muestra de la difícil situación social fue el informe que desde la ACN de $\mathrm{P}$ fue remitido en octubre de $1955 \mathrm{al}$ arzobispo de Madrid informando sobre la actuación de los propagandistas en suburbios según los objetivos que por el arzobispado se habían señalado. En la carta se indicaba que no se habían elaborado estudios previos ni por el Estado, ni por el Ayuntamiento, ni por la Iglesia, de modo que la Asociación nombró un propagandista para cada una de las cuarenta y tres parroquias afectadas. Los resultados suministrados al arzobispado fueron los siguientes: se habían censado unas 6.000 cuevas «que podemos calificar de habitaciones infrahumanas». El 16,7 por cien de la población escolar de las parroquias afectadas (unos 750.000 habitantes), carece de escuelas. Incluso en 1960 había un número de 131.361 chabolas y cuevas, 1.238.878 viviendas sin agua corriente, y casi todas las situaciones aflictivas recaían sobre una misma población estimada en cinco millones de habitantes. ${ }^{9}$ Cuestiones todas ellas de la máxima importancia para la ACN de P, pues una de las principales preocupaciones de Ángel Herrera fue siempre la relacionada con las cuestiones sociales.

En cuanto al medio ambiente institucional, se habían producido dos acontecimientos notables en cuya génesis participaron los propagandistas. El primero de ellos el Concordato de 1953, impulsado por el embajador ante la Santa Sede, Joaquín Ruiz-Giménez, y firmado el 27 de agosto de 1953. Que produjo todo tipo de exaltaciones públicas por ambas partes, pero sin que dejara de haber reticencias. ${ }^{10}$

por añadidura, no suelen llevarse a la práctica». Sobre Acción Católica: «Vive en estado lamentable. Hace dos días visité la Ciudad Universitaria y solamente encontré a un chico que llevaba la insignia. En el año 40 y 41 Madrid estaba plagado de insignias». «Ninguno de los que forman parte de la Junta Nacional es capaz de ponerse al frente de un movimiento renovador ni de crear nada. Lo han demostrado ya». Sobre los profesores de religión: «Es inconcebible. Se dan cargos para que cobren nóminas, pero no hay verdadera preocupación por la enseñanza. No se hacen los concursos a pesar de nuestra insistencia. Nunca tendrán las leyes y facilidades que ahora tienen». Archivo Fernando María Castiella. Nota de 22 de noviembre de 1957. Real Academia de la Historia.

${ }^{9}$ Informe de Francisco Guijarro Arrizabalaga, Presidente de la ACN de P entre 1953 y 1959, y Director Nacional de Cáritas desde febrero de 1963. Reflexiones ante el Día Nacional de la Caridad publicadas en Ya el día 13 de junio de 1963.

${ }^{10}$ Comenta sobre ello el Cardenal Tarancón: «Se produjo un cierto malestar en los ambientes eclesiásticos y políticos cuando el padre Lombardi -a quien todos consideraban como confidente de Pío XII- dijo, en una reunión de La Granja, con ocasión de una tanda de ejercitaciones de 'Un Mundo Mejor', que el Papa se negaba a ratificar en el Concordato el privilegio de presentación del Estado para el nombramiento de obispos, y que tan sólo por las presiones, muy fuertes, que había recibido de distintos sectores de la Iglesia, lo había concedido, aunque lo lamentaba hasta con lágrimas después de la firma. Esta confidencia del padre Lombardi produjo una discusión muy seria en círculos amplios de la Iglesia. Consiguió que se iniciase una especie de contestación no sólo con respecto a ese privilegio del Estado, sino a los privilegios eclesiásticos que se habían conseguido. En general se 
El segundo acontecimiento fue la firma de los acuerdos con los Estados Unidos el 26 de noviembre de 1953. La anterior etapa de aislamiento internacional había concluido. En todo ello fue básica la labor de los propagandistas Alberto Martín Artajo, Joaquín Ruiz-Giménez y Fernando María Castiella. De todo ello cabe deducir que el catolicismo político y social podía tener aún mucho que aportar, y la ACN de P podía igualmente seguir siendo para ello un instrumento útil para la Iglesia.

\section{LA ACN DE P ENTRE 1953 y $1965^{11}$}

En 1953 tuvieron lugar las elecciones para nombrar un nuevo presidente que sustituyese a Fernando Martín-Sánchez, el hombre que desde 1935 gobernaba la Asociación, y persona elegida por Ángel Herrera para sucederle. Dígase que, pese a dejar de ser presidente, su influencia seguía siendo relevante, pues no en vano la renovación del censo que se produce en la posguerra se efectúa bajo su mandato. Había logrado reinsertar a la ACN de P dentro del nuevo ámbito histórico, no sin dificultades, a través de una institución regida por unos estatutos que le otorgaban un alto grado de autoridad. Tales estatutos serían reformados en 1954, no sin serias discusiones, en las que afloraron las divergencias

creía comúnmente que la firma del Concordato no era tan sólo beneficiosa para el Estado, sino también para la Iglesia. Pasados los años, hemos de constatar que pronto nos dimos cuenta muchos de que la firma del Concordato había hecho más difíciles las relaciones Iglesia-Estado en España». Enrique y Tarancón, V. 1996. Confesiones: 151-152 Madrid: PPC. De parte del Estado venía a suceder algo parecido. Incluso en los primeros años se produjeron ciertas diferencias; así lo manifiesta, por ejemplo, la carta remitida el 4 de abril de 1956 a Alberto Martín Artajo, ministro de Exteriores, por el embajador en el Vaticano, Castiella, en relación con los nombramientos de obispos auxiliares: «Dicha práctica (acreditada por una larga serie de casos que no es necesario citar) supone nada menos que arruinar el artículo VII del vigente Concordato entre la Santa Sede y España, anulando en gran medida los efectos, ya muy parcialmente beneficiosos, del Acuerdo sobre el modo de ejercicio del privilegio de presentación suscrito por el Ministro Señor Serrano Súñer y el Nuncio Mons. Cicognani el 7 de Junio de 1941. El Acuerdo que acabamos de mencionar representó ya, como todos sabemos, una serie de importantes renuncias por parte de España a los tradicionales privilegios que su acendrado catolicismo y sus servicios a la Iglesia romana le habían concedido.»... «Ahora bien, el procedimiento actualmente seguido por la Nunciatura Apostólica de Madrid, nombrando unilateralmente Obispos Auxiliares siempre que lo juzga oportuno, supone, en gran parte, la anulación en sus efectos prácticos, del citado Artículo VII del Concordato». ... «..la Nunciatura Apostólica procede a los nombramientos de Obispos Auxiliares sin formular, ni aún por motivos de cortesía, consulta alguna a los Departamentos ministeriales interesados». Archivo del Ministerio de Asuntos Exteriores. Correspondencia con Embajada de España ante la Santa Sede.

${ }^{11}$ El desarrollo de la Asociación en la época ha sido descrito en mi obra de reciente publicación. Ver Martín Puerta, A. 2010. Historia de la Asociación Católica de Propagandistas, (1953-1965): Madrid: CEU Ediciones. Para la época inmediatamente anterior ver: Barreiro, C. 2010. Historia de la Asociación Católica de Propagandistas, (1935-1953): Madrid: CEU Ediciones. 
políticas. Francisco de Luis, el hombre fuerte de La Editorial Católica era hombre extremadamente contrario a Franco, afecto a la línea juanista de Gil Robles -antiguo propagandista con quien estaba en contacto-, $\mathrm{y}$ vino a generar notables enfrentamientos contra la línea de continuidad prevista desde la Presidencia. En efecto, el nuevo presidente, Francisco Guijarro Arrizabalaga, inspector del Timbre de profesión, se encontró inicialmente con una dura oposición en el Centro de Madrid, que refleja claramente en sus memorias Federico Silva Muñoz. Éste último era el hombre designado por Martín Sánchez para dirigir a los jóvenes y pasaría a ser el nuevo Secretario General. El nuevo presidente promovería la indicada reforma estatutaria, en línea de una mayor participación de los socios, buscando una institucionalización que rebajara la línea fuertemente presidencialista impresa por el fundador y su sucesor en la Presidencia. Francisco Guijarro era un hombre absolutamente ajeno a la política, ello en un momento en que no son pocos los propagandistas que ocupan notables cargos públicos. Pero su objetivo consiste en aumentar la tensión espiritual de la Asociación y en promover la presencia en obras sociales. Así por ejemplo, colaborando en misiones de tipo espiritual y de apostolado, en la lucha contra el chabolismo o colaborando con Cáritas, presidida en ese momento por el propagandista Jesús García Valcárcel. Será, por otra parte, hombre distante de las cuestiones polémicas. Así, entre 1956 y 1958 tiene lugar una fuerte lucha de poder en el seno de La Editorial Católica. El anterior hombre fuerte, Francisco de Luis, pasará a ser Consejero Delegado de Administración, ello a instancias de Ángel Herrera, mientras la persona de confianza de éste, José María Sánchez de Muniáin, ejercerá el cargo de verdadero relieve, el de Consejero Delegado de Redacción. De Luis no aceptará la nueva situación, creciendo la tensión en la editorial hasta el punto de que en 1958 el propio Herrera vino desde Málaga para imponer una solución: la personalidad de máximo relieve en la editorial pasaría a ser Alberto Martín Artajo, que ya había dejado el ministerio de Asuntos Exteriores el año anterior. Pero en todo ello nada tuvo que ver Francisco Guijarro: la impronta de Herrera en las obras, especialmente en La Editorial Católica, se sentiría hasta el fin de su vida. Guijarro, no obstante su discreción, sí dejó su huella en la que con el tiempo pasaría a ser la principal obra de la Asociación: el Centro de Estudios Universitarios, en esas fechas órgano docente del Colegio Mayor de San Pablo. No faltarían problemas en su senda de consolidación a ambas entidades: el CEU, creado en 1933, como el colegio, con su imponente -y costosa- construcción, hubieron de hacer frente a varias crisis financieras durante aquellos años. Serían resueltas gracias a generosas donaciones de ciertos socios, entre los que destaca José María SánchezVentura, notario que sería director del colegio y, con el tiempo, último ministro de Justicia de Franco.

Próxima a celebrar su cincuentenario, se hacen públicos los datos en su Boletín 639 y 640 de 15 y 30 de agosto de 1958, que vienen a reflejar la influencia 
de la Asociación: 269 socios trabajaban en la Administración Pública. ${ }^{12}$ Otros 199 se dedicaban a la enseñanza. ${ }^{13}$ Y 173 a actividades productivas, más 44 a periodismo y cine. ${ }^{14}$ En cuanto al número de propagandistas comprometido por actividades, el desglose era el siguiente: 435 en apostolado seglar 288 en obras de difusión del pensamiento, 204 en obras de caridad, 118 en obras de enseñanza, 101 en obras de piedad, 45 en actuaciones económico-sociales, 21 en actividades culturales y 79 sin actividad, siendo compatibles, lógicamente, varias actividades entre sí. En el sector de actividades sociales colaboraban 139 a través de las Conferencias de San Vicente de Paúl, 39 en Cáritas, 18 en protección de menores, y 11 en protección a la mujer. ${ }^{15}$

Para dar idea de la presencia política de los propagandistas por esas fechas se ofrecía en el Boletín 708 de 15 de agosto de 1961 la siguiente información sobre socios que participaban en las comisiones de las Cortes Españolas. Asuntos Exteriores: Francisco Jiménez Torres, Joaquín Ruiz-Giménez Cortés y Alberto Martín Artajo. Comercio: Ramón Hermida. Educación: José Corts Grau y Fernando Martín-Sánchez Juliá. Hacienda: Luis Coronel de Palma, Alfredo López Martínez, Fermín Zelada de Andrés Moreno y José Sinués Urbiola. Información: Antonio González Martínez, Alfredo López Martínez, Fernando Martín-Sánchez Juliá y José Sinués Urbiola. No se mencionaba, por ejemplo, a Mariano Puigdollers ni a Adolfo Muñoz Alonso.

Pese a lo dicho anteriormente, ha de recalcarse que la mayoría de los propagandistas no se hallaba dedicada a cuestiones políticas, sino de tipo apostólico y social. La evolución del censo de la época es la siguiente:

${ }^{12}$ La distribución de este grupo era: 38 ocupaban un cargo público; 16 eran Agentes de Bolsa y Corredores de Comercio; 14 eran fiscales; 10 jueces; 7 magistrados; 7 secretarios judiciales; otros 10 trabajaban en la Administración de Justicia; 42 eran militares; 23 notarios; 10 registradores; 21 trabajaban en Hacienda; 7 eran diplomáticos; 17 en la Seguridad Social; 9 en los sindicatos; 5 en Telégrafos; 25 en Vivienda, y 7 se ocupaban de cuestiones de beneficencia.

${ }^{13}$ La distribución era: 5 académicos; 53 catedráticos de universidad; 23 catedráticos de enseñanza media; 46 profesores; 49 maestros; 18 en otras actividades relacionadas.

${ }^{14}$ Había 10 directores de diarios, 2 de revistas semanales y uno de publicación mensual.

${ }^{15} \mathrm{El}$ desglose de las actuaciones en el primer grupo, apostolado seglar, era el siguiente: 263 propagandistas en Acción Católica, 66 en Congregaciones Marianas, 48 en asociaciones de Padres de Familia, 31 en asociaciones Profesionales, 14 en Cursillos de Cristiandad, 10 en Obras Apostólicas Familiares y 3 en el Movimiento Mundo Mejor. Concretamente 41 propagandistas ocupaban presidencias en Acción Católica a niveles parroquial y diocesano, y en su Junta Técnica Nacional ocupaban la presidencia, dos vicepresidencias, secretaría y 15 vocalías. 


\begin{tabular}{|c|c|c|c|c|c|}
\hline Año & $\begin{array}{c}\text { Numerarios } \\
\text { activos }\end{array}$ & $\begin{array}{c}\text { Numerarios } \\
\text { cooperadores }\end{array}$ & $\begin{array}{c}\text { Inacritos } \\
\text { activos }\end{array}$ & $\begin{array}{c}\text { Inscritos } \\
\text { cooperadores }\end{array}$ & Total \\
\hline 1956 & 265 & 55 & 178 & 67 & 565 \\
\hline 1957 & 279 & 51 & 182 & 68 & 580 \\
\hline 1958 & 211 & 58 & 210 & 136 & 615 \\
\hline 1960 & 348 & 50 & 210 & 60 & 668 \\
\hline 1961 & 356 & 47 & 245 & 55 & 703 \\
\hline 1962 & 360 & 46 & 241 & 54 & 701 \\
\hline 1963 & 368 & 41 & 223 & 50 & 682 \\
\hline 1964 & 369 & 39 & 206 & 51 & 665 \\
\hline
\end{tabular}

El siguiente período de la Asociación, entre 1959 y 1965, verá en la Presidencia de la ACN de P a Alberto Martín Artajo. Letrado del Consejo de Estado, antiguo Presidente de la Acción Católica y brillante ministro de Exteriores entre 1945 y 1957, pasará a ser el hombre de Herrera para reconducir la línea de La Editorial Católica desde 1958. Su período presidencial coincidirá con uno de los momentos críticos de cambio, no sólo en España, sino en Europa y en la Iglesia. Se producen en esas fechas unos puntos de inflexión que modificarán las líneas históricas de tal modo que ni España ni el mundo serán ya iguales pocos años más tarde. Elementos que es imprescindible rememorar si se pretende captar la naturaleza de los profundos cambios que van a producirse.

Hecho notable en la evolución del sistema español fue el cambio de gobierno de febrero de 1957, que, dando lugar a la entrada de los llamados tecnócratas, modificó la dirección política y económica de España. Sólo dos en el gobierno nominalmente, Mariano Navarro Rubio y Alberto Ullastres, pero poco a poco se irían modificando los aspectos del régimen más vinculados a las formas de la posguerra. Un hecho sería definitivo: el Decreto-Ley de 21 de julio de 1959 avalando el contenido del Plan de Estabilización, aprobado en Cortes el 28 de julio de ese año. Comenzaba una etapa de estricto control de la inflación y de liberalización, acompañada de una devaluación de la peseta -el cambio pasó de 42 pesetas/\$ a 60 según decreto de 17 de julio publicado en BOE del día 20 - y de ayudas del exterior. Suponía la inserción de España en los organismos económicos internacionales y en el ámbito económico de Occidente, lo que dejaba atrás definitivamente las derivaciones de la autarquía. Mariano Navarro 
Rubio comentará sobre el único propagandista en ese gobierno, Fernando María Castiella, nuevo ministro de Asuntos Exteriores: «En lo que a mí respecta, fue, quizá -y sin quizás- el defensor más decidido del Plan de Estabilización desde el primer momento. Advirtió claramente que nuestra política exterior necesitaba librarse del 'sambenito' de vivir en un país mal administrado». «Preparó rápidamente el contacto con los organismos internacionales -Fondo Monetario Internacional, Banco Mundial y OECE- y logró que los ministros de Hacienda y Comercio fuésemos como miembros recién nombrados a la reunión que se celebró en Nueva Delhi en septiembre de 1958». España era miembro del FMI y del Banco Mundial desde julio de 1958, encontrándose en la OECE desde mayo de ese año.

Conexo con el cambio de estructuras sería también el hecho de promulgación de la ley de Principios del Movimiento Nacional de 1958, que preveía formas orgánicas de participación. Fueron constantes los editoriales de $Y a$ reiterando la necesidad de promover la participación política, como también las modificaciones necesarias en tal sentido. Entre muchas y reiteradas peticiones al respecto, un ejemplo es el del editorial de 31 de marzo de 1963, En pleno desarrollo político, donde se señalaba: «Lo que importa es desenvolver todo el rico contenido que está en germen en los principios y en las instituciones. Así como se habla de un desarrollo económico, así se debe hablar, más que de una evolución política, de un desarrollo político del régimen», a lo que añadía que «para conseguirlo deben estudiarse las reformas precisas». Peticiones que se repetirían constantemente. Así el editorial del día 13 de julio de 1963 La clave de una genuina democracia era un conjunto de observaciones sobre la carta dirigida por el nuevo pontífice, Pablo VI, al presidente de las Semanas Sociales de Francia. Sobre ello se comentaba: «La humanidad está experimentando un creciente proceso de madurez en el orden de la convivencia social y política. La democracia es la forma histórica adecuada para canalizar ese proceso y satisfacer la tendencia democrática, que se viene apoderando de los pueblos como expresión y como cauce de un progreso civil inequívoco e ineluctable de la humanidad». Ello «repercute hondamente en la configuración de un orden constitucional nuevo, ya que el antiguo, que todavía subsiste, está amenazado, felizmente, de ruina». Recordaba a continuación que la Pacem in terris había fijado «orientaciones harto claras en esta línea de renovación de arquitecturas y ensamblajes constitucionales». Finalizaba reclamando la atención a las exigencias sociales y con la siguiente afirmación: «Por ello, tal articulación constitucional es la pieza clave del organismo político de un país. Y en ello reside el secreto último de la democracia nueva, a la luz de la doctrina de la Iglesia». De modo que era bien clara la reiterada postura del periódico, cuya línea editorial era en ese momento dirigida por Alberto Martín Artajo, presidente de la ACN de P desde 1959. 
Otro de los cambios esenciales sería el inicio del proceso de unificación de Europa, habiéndose firmado en Roma en marzo de 1957 los tratados para su creación. Es importante observar la actitud de La Editorial Católica, pues el 30 de marzo destacaba una cabecera del diario Ya: «Pío XII califica de sublime meta política la gran obra de la Europa unida». Se añadía a continuación que días antes el Papa se había dirigido a un grupo de sacerdotes españoles «haciendo un llamamiento para que España entre también por los caminos de la abertura hacia el europeísmo y el universalismo». Una nueva orientación exterior aparecía en el horizonte que forzaría cambios en las posiciones internas. El europeísmo dentro de la Asociación no era nada nuevo, y José Larraz trataba con frecuencia acerca de ello en sus artículos. Es llamativa la larga visión de este antiguo ministro de Hacienda, del que el editorial de Ya del día 14 de 1957 señalaba: «El señor Larraz prevé que llegará un día en que Europa y Rusia se hayan de poner de acuerdo bajo el influjo de la industrialización china». Evidentemente el proceso forzaba hacia una toma de postura que ya estaba en la sensibilidad de muchos propagandistas. Máxime teniendo en cuenta que el Sumo Pontífice tomaba serio interés por la cuestión. De hecho el editorial de 6 de noviembre de 1957 Hacia la comunidad europea, observaba cómo en reciente audiencia de Pío XII a los delegados de la Comunidad Europea del Carbón y del Acero, el pontífice había señalado la necesidad de «federarse realmente», y que era «necesario y urgente comprender su carácter ineludible».

Ahora bien, el período tratado contemplaría otro acontecimiento que vendría a generar cambios definitivos: el 25 de enero de 1959 el nuevo pontífice Juan XXIII había anunciado a los cardenales su intención de convocar un concilio durante una ceremonia celebrada en la basílica de San Pablo Extramuros con motivo de la conmemoración de la conversión de San Pablo. Las sesiones, desarrolladas entre 1962 y 1965, provocarían notables modificaciones históricas en la Iglesia. Analizados los anteriores elementos de cambio, cabe la siguiente reflexión: modificados tanto el gobierno como la legislación del régimen político, cambiado el modelo económico, surgidas nuevas estructuras de integración en Europa y renovada la Iglesia, era evidente que todo ello tenía que forzar a cambios en el interior de la ACN de P. Una institución creada para la proyección del catolicismo en la vida pública tenía, por fuerza, que generar corrientes de adaptación a las nuevas formas.

\section{LOS MINISTROS PROPAGANDISTAS DE LA ÉPOCA}

Tal como se ha dicho nunca ha sido la política la mayoritaria actividad de los socios de la ACN de P, pero siempre ha habido personalidades con influencia en el mundo de la política. Cuatro fueron los ministros propagandistas en la etapa tratada, y ciertamente personajes bien destacados. 


\section{Joaquín Ruiz-Giménez Cortés (Madrid, 1913. - Madrid, 2009.)}

Hijo de quien fue en dos ocasiones ministro de gobiernos liberales presididos por Romanones, había pertenecido durante la República a la Asociación de Estudiantes Católicos, llegando a ser su presidente. Era Licenciado en Filosofía y Letras y Doctor en Derecho por la Universidad de Madrid, y fue Alférez Provisional de Artillería durante la guerra. Trabajó como profesor ayudante de Mariano Puigdollers desde 1940, y en 1943 obtuvo por oposición la Cátedra de Filosofía del Derecho y Derecho Natural en Sevilla. En 1939 fue propuesto por el cardenal Gomá como representante español de la Confederación Iberoamericana de Estudiantes Católicos, y a los veintiséis años fue nombrado Presidente Mundial de la rama de estudiantes de Pax Romana. En septiembre de 1946 fue llamado por Alberto Martín Artajo para ser el primer presidente del Instituto de Cultura Hispánica. En el Instituto de Estudios Políticos, y por indicación de Pla y Deniel y de Artajo, intervino en modificaciones sobre el Fuero de los Españoles y sobre la Ley de Sucesión. En 1948 fue nombrado embajador de España ante la Santa Sede, desde donde promovió el que luego sería Concordato de 1953. Sería nombrado Ministro de Educación Nacional en 1951, sustituyendo al también propagandista Ibáñez Martín. Nada más llegar al ministerio, Ruiz-Giménez emprendió una reforma que, si bien no tuvo dificultades en su aplicación, le generaría prolongadas, graves y soterradas inquinas: la modificación de las normas de acceso para la plaza de catedrático de universidad, sistema que había dado lugar a acusaciones de favoritismo. La modificación dejaría en dos sobre cinco el número de miembros del tribunal nombrados por el Ministerio, frente a los cinco anteriores. En efecto, en plena época de Ibáñez Martín, se promulgaba la Ley de 29 de julio de 1943 sobre Ordenación de la Universidad Española, que sobre la cuestión tratada decía:

Artículo 58. El ingreso en el Cuerpo de Catedráticos numerarios de Facultad de las Universidades se hará mediante oposición, cuyo procedimiento será objeto de un Reglamento, de acuerdo con los siguientes principios:

b) La oposición se realizará siempre en Madrid, en turno único y ante Tribunal nombrado por el Ministerio de Educación Nacional y constituido por cinco miembros, de los cuales tres, como mínimo, han de ser catedráticos numerarios de la misma disciplina o análoga; uno podrá ser designado entre personas especializadas en la materia, y el Presidente deberá pertenecer al Consejo Superior de Investigaciones Científicas, al Consejo Nacional de Educación o reales Academias.

El Decreto de 7 de septiembre de 1951 por el que se regulaba la forma de nombrar los Tribunales para las oposiciones a Cátedras de Universidad reducía el anterior sistema de pleno arbitrio del titular del ministerio hasta una influencia directa de como mucho dos miembros sobre cinco; aunque sobre su forma de aplicación no dejó de haber discrepancias. 
Hito notable fue la Ley de 26 de febrero de 1953 sobre Ordenación de Enseñanza Media, que proveería al sistema educativo español de un excelente instrumento, pero que supuso un enfrentamiento con ciertos sectores eclesiásticos que temían ingerencias gubernamentales. La persona a la que se encomendaría sacar adelante el proyecto sería José María Sánchez de Muniáin, catedrático de Estética, miembro del Consejo Superior de Investigaciones Científicas y también propagandista. Ruiz-Giménez, en el viaje que efectuó a Roma para despedirse como antiguo embajador, comunicó su intención de reformar las enseñanzas medias. A su regreso comentó al cardenal primado, Pla y Deniel, su deseo de consensuar la ley con la Comisión Episcopal de Enseñanza y, en su caso, con la Conferencia de Metropolitanos. Ya el 21 de octubre de 1951 la Junta de Padres Provinciales había enviado una nota defensiva comunicando a $Y a, A B C$ y Ecclesia su conformidad básica con el plan vigente. Regulación que se había generado en 1938 sobre la marcha, y que, lógicamente, había de adaptarse. El ministro argumentaba a favor de la nueva norma señalando que la Ley de 1938 no mencionaba expresamente los derechos de la Iglesia, sino sólo los de centros privados, de modo que colegios privados no católicos podrían apoyarse en esa ley. Por otro lado se regularía la actuación de la Inspección del Estado para exigir el cumplimiento de los planes de estudio y de la capacitación del profesorado, además de llevarse los exámenes de grado a capitales de provincia y ciudades intermedias. Buscando la independencia y ecuanimidad de los tribunales se iría hacia una composición mixta. Aunque Ruiz-Giménez deseaba una solución consensuada no pudo evitar el enfrentamiento con el sector de la enseñanza más hostil a cualquier incremento del control por parte del Estado. Incluso entre monseñor Olaechea, arzobispo de Valencia, y el primado, hubo algún tipo de fricción, ante la hostilidad abierta del primero a la reforma.

Vista la situación, desde Roma se decidió que sería la Conferencia de Metropolitanos la que negociaría con el Gobierno, que, a través de carta de Ruiz-Giménez a Pla de 12 de marzo de 1952 manifestaba haber tomado el acuerdo «de someter a la consideración de la Santa Sede y de Vuestra Eminencia Reverendísima, aquellos extremos que, por referirse a la enseñanza no oficial, son susceptibles de negociación y acuerdo con la Jerarquía Eclesiástica, según lo prevenido en el Convenio de 7 de junio de 1941». Nuevas discusiones dejaron el proyecto en situación complicada. El 29 de septiembre de 1952 la Conferencia de Metropolitanos publicó un texto manifestando el deseo de transacción, donde se empezaba recordando al gobierno su obligación de atenerse a lo pactado en los acuerdos vigentes de 7 de junio de 1941 y 16 de julio de $1946 .{ }^{16}$ Por su parte Olaechea volvió a reiterar su oposición en una carta pastoral de 25 de

${ }^{16}$ Iribarren, J. 1974. Documentos colectivos del episcopado español. 1870 - 1964: 267-291 Madrid: BAC.

Hispania Sacra, LXVII

135, enero-junio 2015, 303-338, ISSN: 0018-215X, doi: 10.3989/hs.2015.009 
diciembre de 1952; allí se reafirmaba sobre lo dicho en la pastoral reproducida en el número 577 de Ecclesia de 2 de agosto de 1952, defendiendo la normativa de 1938. Finalmente la Ley de 26 de febrero de 1953 sobre Ordenación de Enseñanza Media aparecería publicada en el BOE del día veintisiete. Un editorial publicado en el número 608 de Ecclesia de 7 de marzo de 1953 manifestaba finalmente su criterio, que en términos generales podía evaluarse como favorable. ${ }^{17}$ Ahora bien: pese a que la ley había salido adelante, ello no había sido sin un cierto desgaste del ministro.

Mayor erosión aún le supuso la polémica cultural iniciada sobre la actitud ante Ortega con la publicación de los siguientes libros de autores jesuitas: Ortega y Gasset. Su persona y su doctrina (1942) y La ruta mental de Ortega (1948) de Joaquín Iriarte; José Ortega y Gasset. Pensamiento y trayectoria (1943) y La crisis del historicismo y otros ensayos (1945) de José Sánchez Villaseñor; y finalmente Filosofía y vida. Cuatro ensayos sobre actitudes (1946) de Juan Roig Gironella. El común denominador era el intento de probar el carácter anticatólico de la filosofía orteguiana. Menos discusiones había acerca de Unamuno, autor ya fallecido en 1936, acerca del cual se daba mayor unanimidad en cuanto a la consideración de su escasa ortodoxia. Ahora bien: ambos autores eran defendidos por los intelectuales falangistas, y desde las páginas de sus publicaciones se tomaba postura a favor de una línea que venía a contrastar con la seguida por Arbor, como igualmente por una buena parte de la jerarquía de la Iglesia. Lo peculiar del asunto es que Arbor era una revista dependiente de un organismo como el CSIC, con lo que desde el propio ámbito universitario se atacaba la postura del ministro de Educación Nacional. ${ }^{18}$ La polémica entre Rafael Calvo Serer y Pedro Laín Entralgo tuvo inicialmente características de debate puramente cultural. La obra de Laín España como problema de 1948, sería

\footnotetext{
${ }^{17}$ Se decía en él: «La Santa Sede hubiese podido llevar directamente las negociaciones con el Gobierno; sin embargo en su altísima prudencia, ordenó a la Conferencia de Metropolitanos, organismo representativo el más autorizado de la Jerarquía eclesiástica española, que estudiase el proyecto y procurase que quedasen salvaguardados los derechos de la Iglesia, pero reservándose la Santa Sede la decisión definitiva en este importante asunto». Se reconocía: «Es muy digno de notar y alabar el respeto que en las Cortes se ha guardado a la inspección de la Conferencia de Metropolitanos, y en su consecuencia, al mínimum convenido entre la Iglesia y el Gobierno...». Se manifestaba, no obstante: «No creemos que la nueva ley aprobada y promulgada sea inmejorable. Es más, esperamos que en algunos puntos de los derechos de la Iglesia sea mejorada, ya por disposiciones meramente civiles en el orden económico, ya en el futuro concordato que está negociando el Gobierno con la Iglesia. Mas creemos que ella ofrece un desenvolvimiento digno a los colegios de enseñanza media de la Iglesia....». Por último recalcaba las diferencias que se reconocían en materia de inspección.

${ }^{18}$ En mi libro Ortega y Unamuno en la España de Franco, publicado en Ediciones Encuentro el año 2009, he descrito el desarrollo de la polémica desde sus comienzos en la posguerra hasta sus últimos estertores en los finales de los años cincuenta. Dos obras de Unamuno, Del sentimiento trágico de la vida y La agonía del cristianismo, aparecerían inscritas en el Índice de libros prohibidos por decreto de la Suprema Congregación del Santo Oficio de 30 de enero de 1957.
} 
replicada por España sin problema publicada en 1949 por Rafael Calvo Serer. De momento fue una polémica cortés entre intelectuales, que iría subiendo de tono, donde había discrepancias, pero también coincidencias. La publicación por Rafael Calvo de un artículo en la revista monárquica Écrits de Paris contra la apertura cultural concluiría con una sanción contra Calvo, que se quedó con el ejercicio de su cátedra en la Universidad, pues el BOE de 11 de noviembre recogía su cese como vocal del pleno del CSIC. Ahora bien, desde el momento en que Laín fue nombrado rector de la universidad de Madrid, como Antonio Tovar rector de la universidad de Salamanca, y además el ministro incorporaba a su equipo a falangistas como Pérez Villanueva y Fernández Miranda, la controversia subía de nivel y cobraba carácter político. No habían faltado declaraciones eclesiásticas. Así la carta pastoral de diciembre de 1953 La restauración cristiana de la cultura, del obispo de Astorga, Don Jesús Mérida, que, tras exponer los principios sostenidos por la Iglesia en materia de docencia, criticaba la modificación del sistema de acceso a las cátedras universitarias. En cuanto a Ortega y Unamuno se decía: «no es tolerable que se les erija en maestros indiscutibles del pensamiento español y guías de la juventud universitaria, y se les exhiba ante los jóvenes, siempre 'menores de edad' intelectualmente como escritores intachables y ortodoxos, y no se haga mención de sus errores y de los riesgos de su inconsiderada lectura». Aunque nada comparable a la carta pastoral publicada el 19 de septiembre de 1953 por el obispo de Las Palmas, Don Antonio Pildain, anticipándose a las celebraciones del centenario de la universidad salmantina, a celebrar con presencia de Franco entre los días 8 y 12 de octubre. La carta, con toda rotundidad, se titulaba Don Miguel de Unamuno, hereje máximo y maestro de herejías. De modo que era evidente el deterioro de la posición del ministro, que además, veía cómo el propio Boletín de la $A C N$ de $P$ recogía las declaraciones episcopales más hostiles a su propia línea.

El final de la presencia de Joaquín Ruiz-Giménez en el gobierno tuvo lugar como resultado de los graves incidentes que se desarrollaron en Madrid el 9 de febrero de 1956. Un estudiante del Frente de Juventudes recibiría un disparo en la cabeza, en momentos en que ya se habían producido fuertes enfrentamientos en la Facultad de Derecho, que incluso fue asaltada por falangistas contra estudiantes hostiles al SEU. Aunque el disparo fue efectuado por error desde las filas de los falangistas, se tardó muchos años en saber lo realmente sucedido. Serían cesados Ruiz-Giménez, considerado débil y demasiado tolerante, y el Secretario General del Movimiento, Raimundo Fernández Cuesta. La realidad es que el ministro de Educación venía a padecer la crisis del SEU, un organismo que, pese a su presencia universitaria, era completamente ajeno a él. Con posterioridad iniciaría una línea de reticencias hacia el sistema, manifestándose primero partidario de autentificar las vías representativas reconocidas legalmente, y luego, desde la revista Cuadernos para el diálogo, cuyo primer número corresponde a 1 de octubre de 1963, manifestaría una abierta línea de separación del régimen. 
Sobre su evolución política basta comparar dos manifestaciones no muy distantes. En la conferencia Convivencia y libertades públicas que pronunciaría en los locales de la ACN de P, cuyo extracto fue publicado el 18 de octubre de 1963 en el diario Ya, diría: «No se alude expresamente en la encíclica (Pacem in terris) al complejo problema de la unidad o la pluralidad de partidos políticos. No queda, pues, eliminada la posibilidad de la representación orgánica. Pero, honestamente, hay que decir que los principios de la encíclica preconizan más bien un sistema pluralista de grupos politicos intermedios entre el individuo y el Estado. En todo caso, en los países -como España-donde se mantenga una representación orgánica es indispensable que sea radicalmente auténtica y efectiva, so pena de condenarla en un plazo más o menos corto a su desaparición». Ahora bien, en otra conferencia pronunciada en la ACN de P que se publica en el Boletín de 15 de septiembre de 1964 se encuentran las siguientes ideas: «... la democracia orgánica, entendida en el sentido de la terminología de los años cuarenta, era un sistema de representación 'posible' y hasta conveniente en un país en vías de reconstrucción, pero bajo una doble condición: la autenticidad representativa y la apertura hacia formas más flexibles de ordenación política. Lo más grave es que la mayor parte de las veces que se ha preconizado la sustitución de la democracia pluralista de partidos, clásica u occidental, por un sistema de democracia orgánica, no se ha puesto realmente en práctica, sino que ha funcionado un sistema autocrático, de gran concentración de poder; y esto ha acarreado un tremendo desprestigio de aquella fórmula». Finalmente, a raíz de un enfrentamiento en las Cortes con el procurador falangista Jesús Fueyo -llegando a agarrarse por las solapas-en diciembre de 1964, fue a visitar a Franco para decirle que no deseaba seguir como procurador. Curiosamente, Franco le abrazó en su despedida. ${ }^{19}$

\section{Alberto Martín Artajo Álvarez (Madrid, 1905. - Madrid, 1979.)}

Letrado del Consejo de Estado, había ingresado en el cuerpo el 5 de abril de 1930. Por Decreto de Azaña de 18 de agosto de 1936 quedaba separado del servicio y dado de baja definitivamente en el escalafón. Hubo de abandonar su domicilio y ocultarse; yendo en su busca, una brigada de investigación asaltó y saqueó su domicilio. Fue nombrado Secretario General del Consejo de Estado por decreto de 29 de noviembre de 1940 con sueldo anual de veinte mil pesetas. Cesaría el 20 de julio de 1945 por nombramiento como ministro, y se reincorporaría el 26 de febrero de 1957. Entre 1949 y 1945 presidió la Junta Técnica de Acción Católica, pero ha de recordarse, pese a la imagen «parroquial» que hoy

\footnotetext{
${ }^{19}$ Sobre el recorrido de Ruiz-Giménez ver Santamarina, Á. 1977. Joaquín Ruiz-Giménez. Perfil humano y político: Madrid: Editorial Cambio 16.
} 
se tiene de tal organización, que fue creada con objetivos bastante más amplios: generar un movimiento católico del que pudieran surgir líderes en todos los campos de actuación social, uno de ellos la política. ${ }^{20}$ Ya se ha comentado cómo Artajo fue nombrado ministro de Asuntos Exteriores en 1945 ante la necesidad de ofrecer una imagen distinta del régimen, ya finalizada la guerra mundial y derrotados los países con los que España había mantenido unas especiales relaciones, y de los que se había recibido cierta influencia. Las circunstancias externas no podían ser peores. El 20 de junio de 1945, y promovida por la Unión Soviética en la conferencia de San Francisco, habíase acordado que constase en acta la marginación de España. A lo que siguió la recomendación de 12 de diciembre de ese año de retirar los embajadores en Madrid por parte de todos los miembros de la ONU, proclamándose además la hostilidad hacia el régimen español. Si bien la Asamblea de las Naciones Unidas de 17 de noviembre de 1947 rechazaba por mayoría ratificar la retirada de embajadores, y la III Asamblea de la ONU celebrada en París se abstuvo de tratar el caso. El levantamiento final de la condena tendría lugar en la Asamblea General de 1950 por treinta y ocho votos a favor contra los diez del bloque soviético, aparte de doce abstenciones. El procedimiento seguido por la política exterior española fue escalar indirectamente hacia la meta final a través del previo ingreso en los organismos técnicos de la organización internacional. Una vez que España formaba parte de éstos, antes o después se resolvería la contradicción de la no pertenencia al organismo central, lo que tendría lugar en noviembre de 1955. No parecía haber dudas para nadie en cuanto al acierto del nombramiento de Alberto Martín Artajo, que tuvo que enfrentarse posteriormente a situaciones incómodas, como la independencia de Marruecos, vecino permanentemente causante de litigios de mayor o menor grado, o el asunto de la crisis peronista. Ya se habían producido roces con el gobierno argentino por la cuestión de los pagos del trigo, pero los incendios de iglesias en Buenos Aires por peronistas acabaron por deteriorar del todo la deficiente imagen que tenía Perón entre los gobernantes españoles, pese a las apariencias externas. En cuanto a los criterios políticos de Artajo, ha de decirse que eran bastante transparentes: era partidario de la autentificación representativa del sistema y de que se acabara definitivamente con la identificación entre Falange y Movimiento. Para Arrese -y para los falangistas en general- la línea de Artajo supone un intento de liquidación del Decreto de Unificación de 1937, o, en último término, una fórmula para liquidar el Movimiento. No demasiado conocido es el intento de Artajo de fomentar que la Secretaría General del

\footnotetext{
${ }^{20}$ Es digna de recordatorio la observación del cardenal Tarancón que aparece en la página 325 de sus mencionadas Confesiones: «...la Acción Católica Española tenía un vicio de origen, aunque no quisiéramos reconocerlo: canalizó, no sólo la reacción religiosa, sino la acción religioso-política en la que no se encontraban elementos cristianos exclusivamente». Cabe decir que no fue un fenómeno exclusivamente español.
} 
Movimiento fuera a dar a un tradicionalista, desplazando de la Secretaría las influencias de Falange. Artajo tendría un papel político de primer orden durante la gestión del proyecto de José Luis de Arrese de intentar acrecentar el control de Falange sobre la política española. No era propiamente un proyecto totalitario, como se ha dicho, pero sí una subordinación de toda iniciativa a los criterios de la Secretaría General del Movimiento. Arrese atribuye a Artajo en su memorias la autoría de la actuación que finalmente derriba los proyectos: sospecha permanentemente de él como inductor último de la visita a Franco de los arzobispos de Toledo, Santiago y Tarragona, que presentarán un escrito hostil al proyecto político propuesto; todo ello tras las previas gestiones de Artajo ante la Santa Sede. Ciertamente sería la visita de los obispos a Franco lo que bloquearía definitivamente el proceso, fracaso que Arrese atribuye finalmente a la «Democracia Cristiana». ${ }^{21}$ Ha de decirse que Franco, pese a los grandes servicios prestados por su antiguo ministro, mantenía ciertas desconfianzas hacia él. ${ }^{22}$ Durante la entrevista que tiene lugar en Las Cabezas el 29 de diciembre de 1954 entre Don Juan de Borbón y Franco, éste efectuará el siguiente comentario: «V.A., al referirse a los recientes acuerdos con los EE.UU. y al Concordato con el Vaticano, me ha hecho un elogio merecido de mi Ministro de Asuntos Exteriores Alberto Martín Artajo. Y yo digo a V.A.: «Sí, Martín Artajo es un buen ejecutor cuando se deja dirigir». ¿Quiere esto decir que regateo méritos a ese excelente colaborador? No, pero con la salvedad que acabo de hacer a V.A., por haber sido yo a la vez Jefe del Estado y Jefe del Gobierno».23

Volverá Artajo a ocuparse de la seria cuestión de la reorganización interna de La Editorial Católica, pues -hombre de Herrera- se tiene en él la plena confianza para que juegue el papel previsto por el obispo de Málaga. No en vano

${ }^{21}$ La descripción completa del proceso aparece en Arrese, J.L. 1982. Una etapa constituyente. Testimonio de la marginación de la Falange por Franco: Barcelona: Planeta. Curiosamente, una vez derribado el proyecto en su formato de máximos, se produjo una nueva propuesta de la Secretaría General que venía a reconocer la legalización de cuatro entidades políticas (las cuatro fuerzas que participaron en el alzamiento), o sea Falange, tradicionalismo, monárquicos dinásticos y sucesores de la CEDA, con otro nombre. El cambio de gobierno de 1957 impidió que ello prosperara, aunque Franco inicialmente había dado su visto bueno.

${ }^{22}$ Artajo remitirá a Franco la siguiente carta tras su cese: «Mi general: Me duele la forma en que terminan mis once años y medio de ministro de Asuntos Exteriores a las órdenes de Su Excelencia. Era natural que cesase cuando a Su Excelencia le pareciere que así convenía al servicio del país, pero me apena que, habiendo despachado con Su Excelencia la víspera del Consejo en que anunció la crisis, no me haya confiado sus propósitos, aunque me hubiera pedido secreto bajo palabra de caballero. La verdad sea dicha, mi general; más que una explicación y mucho más que ningún premio, esperaba una palabra de afecto que me parece el único final digno de una colaboración tan leal, tan larga y tan asidua. A muchos ex -ministros he oído quejarse de lo mismo; yo he preferido confiarle mi queja a Su Excelencia para no decírsela a nadie más. En todo caso, ahora como siempre, cuente su Excelencia con la lealtad y el afecto...». Archivo Alberto Martín Artajo. Archivo familiar. (Sin fecha).

${ }^{23}$ Sáinz Rodríguez, P. 1981. Un reinado en la sombra: 227-228 Barcelona: Planeta. 
Herrera había mantenido también conversaciones con Artajo en el momento de la disputa con Arias Salgado sobre la libertad de la prensa. No mucho después de su nombramiento para ocuparse de la editorial pasará a jugar dentro de la Asociación Católica Nacional de Propagandistas el máximo papel: será el nuevo presidente que sustituya a Francisco Guijarro en 1959. Desde su cese como ministro fue constante la atribución que recaía sobre Artajo de estar maniobrando a las órdenes de Ángel Herrera para la constitución de un partido demócrata cristiano. Tal interpretación será desmentida por Artajo con toda claridad en sus declaraciones a una publicación mejicana ${ }^{24}$ Tampoco existen fundamentos más allá de la cábala para pensar que estuviese organizando ningún tipo de fuerza política. Más bien hay datos que prueban lo contrario: cuando en 1962 tenga lugar la reunión de Munich en la que participan algunos propagandistas vinculados a la Asociación Española de Cooperación Europea y a los grupos demócrata cristianos, será el Centro Europeo de Documentación e Información la entidad que juegue un papel determinante para desactivar la actuación de los anteriores; pero el CEDI está presidido en esos momentos precisamente por Martín Artajo. Su criterio constante fue -en la lealtad al poder constituido- fomentar el desarrollo de la participación política. En 1964 la agencia Reuter difundía este comunicado sobre unas declaraciones efectuadas por Artajo: ${ }^{25} \ll$ Ha sorprendido esta semana a los círculos políticos españoles la petición de que España refuerce su Parlamento incluso antes de que el General Franco abandone el poder. Esta petición fue hecha por el ex Ministro de Asuntos Exteriores, Alberto Martín Artajo, en unas declaraciones hechas por radio. La reacción inmediata de los periódicos madrileños fue guardar silencio en sus editoriales... 'La labor común a ambos períodos es dotar al Parlamento de una creciente autenticidad representativa y también de los medios para ejercer un control efectivo sobre la labor del Gobierno', declaró. 'Ambas cosas', continuó diciendo el Sr. Martín Artajo, con una franqueza no común en los discursos políticos de las figuras españolas de segundo plano, 'son necesarias y urgentes y deben iniciarse justamente ahora'». Lo que, por otro lado, se defendía constantemente desde los diarios de La Editorial Católica con toda nitidez, siendo precisamente Artajo el hombre responsable de su orientación general. Su período de presidencia de la ACN

\footnotetext{
${ }^{24}$ Entrevista publicada en el periódico mejicano Mañana de 9 de agosto de 1958. La entrevista tenía lugar con Luis Suárez, antiguo capitán del Ejército de la República, que señalaba en la introducción: «Aunque manifestándose contra el sentido clásico de la democracia, el señor Martín Artajo cree que «nuestra naciente democracia orgánica, nuestro Estado de Derecho, pueden aún recorrer mucho camino, tanto en afinar sus métodos de representación y audiencia de la opinión pública, como en facilitar el ejercicio de las libertades personales, conforme a las normas del Derecho público cristiano». O sea, que la tendencia que representa el señor Martín Artajo, espera y desea cambios políticos, pero parte del mismo principio proclamado por Franco que el régimen corporativo español en otro tiempo inequívocamente y hasta orgullosamente fascista, es ahora una democracia orgánica perfectible».

${ }_{25}$ Archivo Fernando María Castiella. Real Academia de la Historia. Nota de 24 de julio de 1964.
} 
de P entre 1959 y 1965 vendría a insertarse en la segunda fase del régimen de Franco, cuando ya se han modificado muchos de los elementos que generaron el régimen político, y cuando la Iglesia ha optado por una línea de renovación. La adaptación no dejará de generar las mismas dificultades generales que al catolicismo español de la época.

Fernando María Castiella y Maíz (Bilbao, 1907.- Madrid, 1976.)

Catedrático de Derecho Internacional Público y Privado desde 1935, era miembro del Tribunal Permanente de Arbitraje Internacional de La Haya. Se alistó voluntario en la División Azul, y por ser catedrático se le destinó a trabajar en el boletín de aquella unidad militar, cosa que no le satisfizo, por lo que pidió su traslado al frente. Dirigió el Servicio Exterior de Falange y en 1943 el Instituto de Estudios Políticos. Sería igualmente el primer decano de la recién creada Facultad de Ciencias Económicas. En 1949, con Federico de Castro y Antonio de Luna, sería cofundador de la Revista Española de Derecho Internacional, del CSIC. Tras ser destinado como embajador en Perú en 1948, fue enviado a ocupar la embajada ante la Santa Sede en 1951 en sustitución de Joaquín Ruiz-Giménez. Entre 1957 y 1959 sería el titular de la cartera de Exteriores, sustituyendo a Martín Artajo. Son muy conocidas sus intervenciones en relación con el asunto de Gibraltar y su importante colaboración en la financiación de la economía española a raíz del Plan de Estabilización, como igualmente su labor para que España ingresara en los organismos económicos internacionales.

Pero son menos conocidas sus actitudes con respecto a la política interna española. Para empezar ha de decirse que era sumamente reticente en cuanto a cualquier interpretación de tipo integrista. Así, siendo embajador ante la Santa Sede, remite una carta a Carrero Blanco el 19 de abril de 1952, donde indica: «Los españoles, más papistas que el Papa, seguimos resultando incómodos. La propia Jerarquía eclesiástica española, con las intemperancias del Cardenal Segura y los apetitos desenfrenados de las Órdenes religiosas en materia de enseñanza, siguen creando engorros en el Vaticano que, aunque parezca paradójico, quizá quisiera que no fuéramos... $\tan$ buenos». ${ }^{26} \mathrm{O}$ con motivo de la inclusión de las obras de Unamuno en el Índice, comenta así el asunto a Artajo en carta de 31 de enero: ${ }^{27}$ «Además, este hecho, que ha de tener sin duda una repercusión mundial, puede demostrar al extranjero que el estado español

\footnotetext{
${ }^{26}$ Archivo del Ministerio de Asuntos Exteriores. Correspondencia con Embajada de España en el Vaticano.

${ }^{27}$ Archivo del Ministerio de Asuntos Exteriores. Correspondencia con la embajada de España. La carpeta incluye copia del texto del Osservatore Romano con la condena y comentarios.
} 
no es tan hermético ni tan intransigente con ciertos valores como las propagandas enemigas hacen suponer, mientras que algunos elementos adversos al Régimen (léase el Señor Obispo de Canarias, piénsese en el Cardenal Segura) que, debido a esta circunstancia, pasan por liberales o poco menos más allá de nuestras fronteras, se distinguen en realidad por lo contrario. Son -bien claro es para nosotros - los paladines de la intransigencia». Califica a monseñor Pildain -autor de la declaración antiunamuniana de 1953- de «campeón de los democristianos separatistas vascos», alusión a sus actuaciones políticas durante la República, cuando fue elegido diputado por Guipúzcoa en 1931 por el Grupo Vasco-Navarro, constituido por carlistas, miembros del PNV e independientes. Y añade: «Por lo demás, justo y triste es decirlo, el hecho mismo de la condena $\mathrm{y}$, sobre todo, las consideraciones que la acompañan en la primera página del Osservatore Romano del 31 de enero, (véase un amplio y fiel resumen en mi telegrama $\mathrm{n}^{\mathrm{o}} 16$, así como el texto anejo) no parece que hayan tenido lugar -salvando siempre las supremas razones de la Iglesia- en el momento más oportuno y en las más adecuadas circunstancias». Sobre el resultado de la condena, lamenta que «Unamuno será, hoy más que nunca, en vez de un pensador digno de serio estudio, para desbrozar precisamente la verdad del error, una escandalosa bandera política». El efecto final será que sus obras «sean rebuscadas como fruto prohibido y lograrán ahora una influencia, en lo que tienen de negativo, que no alcanzaron nunca». Se lamentaba igualmente de que «cabía esperar que el Nuncio Apostólico, el Episcopado o, si se quiere, la Secretaría de Estado, hubieran informado reservadamente de las intenciones del Santo Oficio -si es que tenían noticias de las mismas- a un Gobierno católico como el nuestro», lo que no sucedió. Recalcaba además que la revista de los jesuitas franceses Études de abril y mayo de 1956 había tratado elogiosamente a Unamuno.

Otro tanto sucedió con las dificultades que tuvo para adecuar la normativa española a los criterios conciliares en lo referente a la libertad religiosa. En septiembre de 1964 el episcopado español reunido en Roma, en el ámbito de las asambleas celebradas con motivo del concilio había tratado acerca del anteproyecto sobre las confesiones no católicas. El cardenal arzobispo de Sevilla había subrayado la conformidad de todos los presentes con el texto del anteproyecto. Se trataba de la adecuación a los nuevos criterios sobre libertad religiosa. En conferencia de prensa, monseñor Enrique y Tarancón, arzobispo de Oviedo, declaraba el 3 de diciembre: «La declaración sobre libertad religiosa va a deslindar bien los campos. En el terreno religioso, los de otras confesiones no pueden considerarse como enemigos, serán hermanos separados o simplemente equivocados. Es un cambio de mentalidad y de postura que yo juzgo trascendental». Añadiendo, no obstante: «La unidad católica es un bien inestimable que hemos de conservar». El 10 de septiembre se había reunido el Consejo de Ministros en el pazo de Meirás, habiendo presentado Castiella -pero sin figurar en el orden del día- un «Proyecto de ley sobre la condición jurídica de los acatólicos y de las confesiones acatólicas en España». En su redacción había 
intervenido el Embajador ante la Santa Sede, Antonio Garrigues y Díaz-Cañabate..$^{28}$ Carrero, Ministro Subsecretario de la Presidencia, escribió personalmente un texto contrario a la totalidad del proyecto. Esencialmente se basaba en considerarlo contrario al segundo principio de la Ley de Principios del Movimiento Nacional, ${ }^{29}$ y ponía serias objeciones al procedimiento seguido. Añadía contra el proyecto presentado por Castiella: «Debo señalar que el procedimiento de negociación del texto no ha sido el correcto. Puesto que era el Gobierno quien debía aprobarlo en última instancia, el Gobierno debió conocer y aprobar el texto inicial antes de ser enviado a la Jerarquía». Añadía Carrero una observación basada en una buena información, pero finalmente de dudosa validez: «Lo mismo que creo que hay muchos Ministros -yo uno de ellos- que no están conformes con el texto del anteproyecto, estoy seguro de que hay muchos Prelados, me atrevería a asegurar que la mayoría, que tampoco lo están». Equivalía ello casi a negar representatividad a la Conferencia de Metropolitanos, como a la comisión por estos nombrada, además de autoproclamarse como correcto intérprete de la doctrina de la Iglesia y del pensamiento de los obispos con independencia de lo que la Iglesia y los obispos dijeran..$^{30}$

${ }^{28} \mathrm{El}$ anteproyecto comenzaba: «Artículo $1^{\mathrm{o}}$ : El Estado español garantiza la profesión y la libre práctica en privado de todas las creencias religiosas, en tanto que el ejercicio de las mismas no atente a los Principios del Derecho Natural, perturbe el orden público o comprometa la unidad espiritual de España. El ejercicio de cualquier derecho que se reconozca a confesiones distintas de la católica, no podrá menoscabar las prerrogativas que corresponden a la Religión oficial del Estado con arreglo a las leyes. Artículo $2^{\circ}$. Las creencias de los españoles en materias religiosas no constituirán, en ningún caso, motivo de desigualdad ante la Ley, que ampara por igual el derecho de todos los españoles sin preferencia de clases ni acepción de personas». Por otro lado se podía leer. «Artículo 19. Las asociaciones confesionales no católicas legalmente reconocidas podrán celebrar, sin previo aviso de las Autoridades, todas las reuniones de carácter religioso que tengan lugar en sus templos o capillas, en el recinto de los cementerios o en otros centros debidamente autorizados. Artículo $20^{\circ}$. Los actos que las Asociaciones confesionales no católicas hayan de celebrar en sus lugares de culto, cementerios y demás centros reconocidos, podrán ser anunciados discretamente para conocimiento de sus adeptos tanto residentes en la localidad como transeúntes». Ver López Rodó, L. 1990. Memorias: 748-754 Esplugues de Llobregat: Plaza Janés. Obsérvese que el Artículo $1^{\circ}$ se adecuaba al régimen confesional de unidad católica.

${ }^{29}$ El Punto II de la ley de 17 de mayo de 1958 decía: «La Nación española considera como timbre de honor el acatamiento a la Ley de Dios, según la doctrina de la Santa Iglesia Católica, Apostólica y Romana, única verdadera, y fe inseparable de la conciencia nacional, que inspirará su legislación». La ley que regularía el ejercicio del derecho a la libertad religiosa aparecería finalmente en el BOE de 1 de julio de 1967.

${ }^{30}$ Sobre la actitud de Carrero refiere Tusell: «Redactó, además, un largo informe en que describía el propósito de Castiella como un intento de conseguir 'benevolencia' exterior que sería, además, recibida 'despectivamente'. La unidad católica era esencial para España, y cualquier intento de hacerla desaparecer resultaría un 'mal servicio a Dios' y una afrenta a los Principios del Movimiento; ésa era la razón 'por la cual nuestros contumaces enemigos tienen tanto interés en quebrantarla'. Se trataba, en fin, de una 'apertura a siniestra' que tendría unos resultados políticos inaceptables. El proyecto quedó detenido, y tardaría en aprobarse otro que el Concilio Vaticano II había hecho inevitable, pero ya no lo redactó Castiella, sino Oriol, el ministro de Justicia nombrado en 1965. Lo sucedido da idea de la oposición de fondo de Carrero a la institucionalización de cualquier pluralismo y de su talante religioso». Ver Tusell, J. 1993. Carrero. La eminencia gris del régimen de Franco: 290 Madrid: Temas de hoy. 
En la carta de Garrigues a Castiella de 27 de agosto de 1964 encontramos una importante explicación sobre la línea seguida por el ministro de Exteriores: «La realidad es que tienes, para llevar adelante este asunto, el pleno asentimiento del Nuncio, representante en España de la Santa Sede, el pleno asentimiento del Episcopado español a través de su organismo correspondiente, y sobre esto, que ya es mucho, tienes toda la razón, toda la justicia, toda la rectitud de intención... Debes, pues, sin la menor duda, llevar el proyecto de decreto al próximo Consejo de Ministros para su aprobación, porque de acuerdo con Monseñor Riberi y de acuerdo con el Arzobispo Morcillo y de los demás Obispos que te han hablado en este sentido, no hay duda que desde todos los puntos de vista es mucho mejor y mucho más conveniente que el estatuto de los protestantes en España se anticipe a las deliberaciones y a las propuestas que sobre materia de libertad religiosa pueda el Concilio acordar». ${ }^{31}$ Garrigues promovía una actitud anticipativa e inteligentemente conservadora, mientras la de Carrero se hallaba irremediablemente destinada a perder todas las posiciones.$^{32}$ La postura de Castiella tendría un coste político y personal que Fraga refiere en sus memorias. En el apartado correspondiente al día 6 de abril de 1965 indica: «La jerarquía eclesiástica designa a monseñor Morcillo para que, en nombre de todos, visite al Jefe del Estado pidiéndole que mueva el proceso de institucionalización y de reformas; era, indudablemente, el mejor interlocutor. Esto levanta un poco el ánimo de Castiella, que está pasando horas bajas. 'Todos me quieren acorralar', me dice». ${ }^{33}$ No obstante, pese a las dificultades, es evidente que fue un hábil transmisor de los criterios de la Iglesia en una materia entonces tan conflictiva, y que implicaba, además de serias modificaciones legislativas, grandes cambios de actitud.

\section{Federico Silva Muñoz. (Benavente, Zamora, 1923. - Madrid, 1997.)}

Había estudiado en el Centro de Estudios Universitarios, donde se licenció en Derecho, ganando ulteriormente plaza por oposición en los cuerpos de Letrados del Consejo de Estado y Abogados del Estado. Era el joven seleccionado por Fernando Martín-Sánchez para renovar la Asociación, de modo que fue promovido a Secretario General, puesto desde el que buscó la conexión de la Asociación con jóvenes de características destacadas. Si bien es conocido por su

${ }^{31}$ Igual criterio se manifestaba en la carta remitida por Antonio Garrigues a Castiella el 7 de septiembre dándole cuenta de las reuniones que había mantenido con el primado y con los arzobispos de Sión y de Madrid-Alcalá, comentando: «Se cierra el paso antes de la declaración del Concilio sobre libertad de conciencia, al peligroso sistema de libertad religiosa y de cultos», a la vez que «da a los protestantes un 'status' que no es más que expresión del derecho natural y de gentes». Archivo Fundación Francisco Franco. Documento 20307.

${ }^{32}$ Archivo del Ministerio de Asuntos Exteriores. Correspondencia con Embajada de España 1963-1964.

${ }^{33}$ Fraga Iribarne, M. 1980. Crónica de medio siglo 1931-1982: 135 Barcelona: Planeta. 
labor como ministro de Obras Públicas, puesto para el que fue nombrado en julio de 1965 , no se conocen tanto algunas de sus actuaciones políticas anteriores. En especial fue relevante su protagonismo en 1964 con motivo del proyecto promovido por José Solís Ruiz, Secretario General del Movimiento, en torno a las derivaciones de la prevista Ley de Asociaciones de Familia. La cuestión no era menor, pues se trataba de desarrollar los cauces orgánicos de participación previstos en la Ley de Principios del Movimiento Nacional, previéndose la elección de procuradores por vía electiva a través de los cabezas de familia. La repercusión política era, por tanto, clara. La maniobra desarrollada desde la Secretaría General del Movimiento consistió en promover la articulación del asociacionismo familiar desde las organizaciones del propio Movimiento presentes en cada municipio. Silva comenta sobre ello en sus Memorias políticas: «Desde el punto de vista de la Iglesia católica suponía una negación del carácter natural y suprapolítico de la familia; y desde el político era, como ya he señalado, un intento enmascarado de controlar las futuras y ya previsibles elecciones de procuradores familiares, pues resulta especialmente importante subrayar que, al menos en el proyecto, a tales asociaciones se les quería atribuir la facultad exclusiva de presentación de candidatos. El arzobispo de Valencia y numerosos obispos me pidieron que me opusiera al proyecto de ley. Alfredo López y la junta nacional de Acción Católica me requirieron en el mismo sentido». Laureano López Rodó ofrece información adicional. ${ }^{34}$ Silva recibió una llamada de monseñor Olaechea, arzobispo de Valencia, invitándole a almorzar. Se encontró allí con todos los metropolitanos, además de monseñor Guerra Campos, Ricote y monseñor Torrella. Concluido el almuerzo, Olaechea propuso remitir un escrito colectivo al Jefe del Estado sobre el proyecto de ley. Hubo aceptación unánime, encomendándose a Silva la redacción del texto dirigido al Presidente de las Cortes, donde se decía: «La Conferencia de Metropolitanos reunida en Madrid me ha encargado le transmita con el fin de que sirva elevarle a S.E. el Jefe del Estado, la profunda preocupación que tiene ante el alcance del Proyecto de

\footnotetext{
${ }^{34}$ «Federico Silva distribuyó a los miembros de la Conferencia Episcopal una nota concebida en los siguientes términos: 'El proyecto de ley de Asociaciones Familiares obedece a principios y orientaciones que pugnan con los principios de la doctrina de la Iglesia y del Derecho Público eclesiástico, que reconoce y ampara la autonomía de la familia, pues como en el preámbulo del citado Proyecto se dice, trátase de asegurar 'su unidad y permanencia, dentro del orden social y político del Movimiento'. Con ello resulta patente que se intenta sustraer a la familia del orden social de la nación para integrarla (...) en FET y de las JONS». Seguía un párrafo especialmente duro: «Si a todo ello se unen los recientes intentos de institucionalización realizados fragmentariamente y al margen de las Leyes Fundamentales del Reino por el Decreto de 18 de junio de 1964 (se refería al que estructuró la Comisión Permanente del Consejo Nacional) en el que despunta un principio de hegemonía de grupo, es fácilmente comprensible la honda preocupación que sentimos por la posibilidad de un resurgimiento extemporáneo, siempre recusable en buena tradición y doctrina cristianas y nacionales, del totalitarismo del Partido». A continuación indica que Silva fue a visitar al Nuncio para ponerle de relieve la disconformidad del proyecto con la doctrina de la Iglesia y rogarle que hablase con Castiella. López Rodó, L. 1990: 495.
} 
Ley de Asociaciones de Cabezas de Familia, sometido a estudio de las Cortes Españolas, pues no cree se acomode a los principios del derecho natural que amparan la constitución de la familia como célula social básica, tanto de la sociedad civil como de la Iglesia, y también porque estima no favorece la unidad de los españoles». Añadirá Silva: «Salí para la casa de Arturo Soria donde vivía don Marcelino, y se lo leí. Le pareció muy bien. Lo firmó y partí para las Cortes con el fin de entregárselo al presidente. Lo recibió don Esteban con viva complacencia y a las pocas horas estaba en manos del Caudillo. Del malhadado proyecto nunca se volvió a hablar» ${ }^{35}$ Desarrolló Federico Silva, por tanto, una actuación similar a la que había seguido en 1956 Alberto Martín Artajo con su oposición a los proyectos de José Luis de Arrese.

REFLEXIÓN SOBRE LOS PUNTOS DE INFLEXIÓN HISTÓRICA DE LA ÉPOCA

La época referida sigue requiriendo aún de estudios históricos que expliquen los cambios producidos, y que afectaron a todo tipo de agrupaciones: ya fueran religiosas, políticas, económicas. En todas ellas se producen variaciones notables como consecuencia de un conjunto de elementos que modifican su curso.

Modificaciones políticas internas, tales como el cambio de gobierno de febrero de 1957 transformarán el formato del régimen. Los antiguos modos de carácter totalitario -aunque en muchos casos no fueran más allá de una desfasada estética externa- irán desapareciendo. La Ley de Principios del Movimiento Nacional de 1958 produjo inicialmente una expectativa de desarrollo político superiores a lo que hoy se piensa. Acogidos a tal interpretación, los propagandistas vinculados a la política defenderían la autentificación del sistema representativo, algo que en muy escasa medida tendría lugar. El siguiente apartado se ocupará en detalle de este aspecto.

Cambios políticos externos, como la mencionada consolidación del proceso de expansión de las Comunidades Europeas hacia una forma de integración política, también a partir de 1957. El horizonte empezará a ser otro. El grupo propagandista, de antiguo vinculado a sectores demócrata cristianos europeos, consideró con gran interés el proceso. Ha de decirse que en tal actuación se manifestaron las dos tendencias políticas existentes dentro de la ACN de P. Con motivo de la reunión del Movimiento Europeo celebrada en Munich los días 7 y 8 de junio de 1962, un sector vinculado desde hacía tiempo a Gil Robles, protagonista de aquellas jornadas, se adhirió a la postura hostil al régimen. Sería el grupo constituido por Fernando Álvarez de Miranda, Juan Luis Simón Tobalina, José Luis Ruiz-Navarro y Francisco Cantera Burgos, pues Íñigo Cavero no era aún miembro de la Asociación. Pero a la desactivación de sus proyectos colaboraron nada

${ }^{35}$ Silva Muñoz, F. 1993. Memorias Políticas: 91-93 Barcelona: Planeta.

Hispania Sacra, LXVII

135, enero-junio 2015, 303-338, ISSN: 0018-215X, doi: 10.3989/hs.2015.009 
menos que Alberto Martín Artajo, presidente de la Asociación, Fernando María Castiella, ministro de Exteriores, y Adolfo Muñoz Alonso, Director General de Prensa. Sin olvidar la nota de descalificación redactada en el ámbito juanista por José María Pemán, Presidente del Consejo Privado de Don Juan de Borbón. El grupo vinculado al sector oficialista había establecido sin embargo una más que notable red de contactos en torno al CEDI, especialmente próximo a la democracia cristiana alemana, cuyos criterios políticos y de cristianismo social compartía.

Cambios económicos substanciales, materializados en el Plan de Estabilización de julio de 1959 dirigidos al saneamiento económico, control radical de la inflación, liberalización económica y eliminación de los vestigios de autarquía. Ello implicó la entrada en un nuevo ámbito de instituciones económicas internacionales (OECE, Banco Mundial, Fondo Monetario Internacional), con serios sacrificios internos. Castiella y la organización de Asuntos Exteriores serían piezas clave para la obtención de financiación exterior.

Cambio religioso estructural, como fue el Concilio Vaticano II. No hace falta señalar que es el acontecimiento que marca un antes y un después. La ACN de P recogió con entusiasmo todos los cambios propuestos y su adecuación a las líneas conciliares fue inmediata. Lo que tenía en el orden interno serias repercusiones, y no sólo de cambio de ánimo: España era un Estado confesional, lo que implicaba también la necesidad de modificaciones jurídicas. Los propagandistas implicados en tales repercusiones normativas, Castiella uno de ellos, como hemos visto, colaboraron eficientemente para impulsar las necesarias adaptaciones.

Lo cierto es que la España de mediados de los sesenta, comparada con la de mediados de los cincuenta, es ya esencialmente diferente, habida cuenta de la existencia de todos esos puntos de inflexión. Los grupos católicos debían trabajar ahora sobre un terreno bien distinto.

\section{EL PROYECTO POLÍTICO DE LOS PROPAGANDISTAS}

Lo primero que ha de decirse es que dentro de la $\mathrm{ACN}$ de $\mathrm{P}$ nunca hubo una sola tendencia política, y desde los mismos inicios del régimen de Franco hubo notables propagandistas situados en posición de distanciamiento. En una primera fase vinieron a estar relacionados con José María Gil Robles, afiliados a la Asociación Española de Cooperación con Europa. En torno a ella surgiría el grupo de oposición al sistema presente en la reunión de Munich de 1962. No obstante, la postura rupturista con respecto al sistema tendió siempre a ser minoritaria. Otros propagandistas de esas fechas, como Fernando Martín-Sánchez, Blas Piñar o Adolfo Muñoz Alonso eran notables partidarios del régimen político.

Cabe, no obstante, hablar de un proyecto -no explícito, pero sí identificable sin dificultad- de los propagandistas implicados en las instituciones políticas. 
Claramente compartido por Alberto Martín Artajo, Fernando María Castiella, Alfredo Sánchez Bella, Federico Silva Muñoz o Luis Sánchez Agesta, y, también durante cierto tiempo, por Joaquín Ruiz-Giménez. En seguimiento de la tendencia corporativista católica de los años treinta y en base a lo señalado en la Ley de Principios del Movimiento Nacional de 1958 se insistió en la aplicación real de lo señalado en tal ley. El Principio VIII preveía el desarrollo participativo por vía de los cauces familiar, municipal y sindical; por su parte el Principio VI mencionaba el reconocimiento de «instituciones y corporaciones de otro carácter», menciones que eran frecuentemente invocadas desde los editoriales del diario $Y a$. Dígase que tanto Ángel Herrera como Fernando Martín Sánchez habían escrito textos críticos con respecto al corporativismo fascista, entendiendo que no eran desarrollos naturales orgánicos, sino creados desde el Estado. No obstante el corporativismo católico era distinto, buscando instituciones que surgiesen de modo natural, discrepándose en último término acerca del papel del Estado. Se trataba, por tanto, de una concepción distinta acerca de la sociedad.

Una carta de 22 de mayo de 1964 remitida a Castiella por el embajador ante la Santa Sede, Antonio Garrigues Díaz-Cañabate, hombre sumamente próximo a los propagandistas, expresa con toda claridad: «Mientras tanto fortalezcamos y desarrollemos más y más nuestra economía y sobre todo llevemos a término nuestro desarrollo político con un tipo de democracia orgánica, pero que sea real; con un tipo de libertad, ni liberal, pero que sea en sus límites, verdadera; con una sociedad de un pluralismo restringido (exclusión del comunismo y marxismo, del ateísmo y de la religiosidad anticatólica, etc.) pero al fin de un pluralismo. Lo demás vendrá por añadidura». ${ }^{36}$ En cuanto al posible reconocimiento de otras fuerzas políticas -en interpretación del Principio VI- había distintos matices, pero el criterio esencial era que las formas orgánicas debían ser las que determinasen lo esencial del sistema representativo; los «partidos»-a reconocer en una u otra forma- no serían los monopolizadores de la representación, sino elementos complementarios para la dinamización política. Por tanto la cuestión considerada como perentoria era la autentificación de la representación orgánica, algo que encontramos reiteradamente defendido por el grupo político propagandista. En una carta remitida a Castiella el 30 de junio de 1965 por el Embajador en Italia, Sánchez Bella, encontramos la siguiente advertencia: «Si el día que el Jefe del Estado falte existen instituciones sólidas, cualquier persona que las encarne podrá llevar adelante la empresa con grandes posibilidades de éxito, dentro de un Estado Presidencialista Coronado. Si estas instituciones, por acción o por inacción, no se crean o se contribuye a no darles prestigio y revestirlas de autoridad, cualquier fórmula que con precipitación se adopte, será flor

\footnotetext{
${ }^{36}$ Archivo del Ministerio de Asuntos Exteriores. Correspondencia con la Embajada ante la Santa Sede 1964.
}

Hispania Sacra, LXVII

135, enero-junio 2015, 303-338, ISSN: 0018-215X, doi: 10.3989/hs.2015.009 
de un día y carecerá de continuidad». Poco antes Sánchez Bella había enviado otra carta a Carrero Blanco el 15 de marzo de 1965, lamentando la poca atención que se prestaba a cuestión tan importante: «...tal vez preocupados exclusivamente en el desarrollo no hayamos dado la debida importancia a este natural proceso de la representación política en todas las escalas», añadiendo: «es de imperiosa necesidad que lo vayamos abriendo paulatinamente». ${ }^{37}$ Era evidente lo que se reclamaba: están defendiendo un régimen del que esperan que ponga en práctica lo que sus propias leyes prevén en cuanto a desarrollo político.

Aunque hoy día tal intento de revitalización de formas orgánicas o corporativistas se considere un dato menor, o meramente de ficción, esa breve etapa suscitó notables esperanzas en muchos. Se abría la posibilidad de poner en práctica unas formas políticas inéditas, y que, confluyendo en un sistema de libertades, restase protagonismo a los tradicionales partidos dándoselo, por el contrario, a los cuerpos intermedios de la sociedad. ${ }^{38}$ Ahora bien: de tales expectativas incumplidas surgirían decepciones que ya no tendrían vuelta hacia atrás. ${ }^{39}$

No se piense, no obstante, que se trataba de un proyecto político semiclandestino. No sólo se defendía lo mismo en las páginas de los diarios de La Editorial Católica -con términos quizá menos explícitos en lo que se refiere al reconocimiento de fuerzas políticas-, sino que el propio Castiella remitía tales cartas a Franco, que generalmente subrayaba los aspectos principales de toda la abundante documentación que recibía. Tratábase de un criterio interpretativo

${ }^{37}$ Archivo Fundación Francisco Franco. Documentos 10718 y 1117.

${ }^{38}$ Sorprendente ejemplo de ello es el contenido de la carta de 10 de marzo de 1966 que Antonio Garrigues remitirá a Franco -con la correspondiente copia a Castiella-, informando al Jefe del Estado sobre el contenido de su entrevista con Pablo VI: «Específicamente me dijo lo siguiente: a este respecto nosotros no queremos más que lo que quiera el Caudillo. Si él piensa que la mejor solución para España es la Monarquía, nosotros apoyaremos la Monarquía. Si él se inclina a otra solución, nosotros nos inclinaremos también a ella. De la misma manera respecto a las fuerzas políticas en que él piense que debe apoyarse el futuro de España dentro, naturalmente, de las fuerzas de inspiración cristiana y católica, como son todas las que constituyen hoy la estructura del Régimen español. Nosotros estaremos también detrás de sus iniciativas». Archivo del Ministerio de Asuntos Exteriores. Correspondencia con Embajada ante la Santa Sede 1966.

${ }^{39} \mathrm{El}$ estancamiento político y las correspondientes desilusiones y distanciamientos generarían igualmente reacciones de defensa del sistema que, ante la no aplicación del modelo propuesto -ya una pura expectativa- exaltaban fases ya pretéritas del régimen. Una lúcida carta de Garrigues a Castiella de 4 de febrero de 1969 exponía la situación y los riesgos con toda nitidez, expresándose del siguiente modo: «... los males a extirpar serían la ley de prensa, la ley de libertad religiosa, el incipiente pluralismo del contraste de pareceres y, en suma, toda forma de institucionalización efectiva. Se trataría, en fin, de un neototalitarismo. Pues bien, en tal supuesto que formulo, tan sólo a título de hipótesis, lo que yo creo estar obligado a hacer desde este puesto es llamar la atención de que si llegara a realizarse, el Régimen vendría a topar, en una medida mayor o menor, según el grado de realización, con la Iglesia. Con la Iglesia española y con la Iglesia Romana»... «Lo que no se puede desconocer es que hoy ya una parte de nuestra Iglesia está situada no contra el Régimen, pero sí en las orillas, en los aledaños del mismo». Archivo Fernando María Castiella. Real Academia de la Historia. 
de lo que debía ser el régimen, efectuado por gentes que buscaban su perfeccionamiento apurando al máximo las posibilidades que la legislación ofrecía. De la mayor claridad es el texto publicado por el propagandista Luis Sánchez Agesta en el número 3 de Cuadernos para el diálogo, revista mensual fundada por Ruiz-Giménez que aparece el 1 de octubre de 1963; dudaba, a esas alturas, de la posibilidad de prescindir de los partidos, aunque rechazaba, no obstante, la posibilidad de reproducir el modelo que alcanza hasta 1936. Los partidos, con ese u otro nombre, no deberían acaparar el monopolio de la representación. La conferencia pronunciada por Ruiz-Giménez en la ACN de P, y publicada en el Boletín de 15 de septiembre de 1964, es una abierta crítica demostrativa de que aún permanece dentro del sistema, pero igualmente de que tiene ya pocas esperanzas en su evolución. En cierto sentido la ruptura de Ruiz-Giménez con el proyecto corporativista era también una separación de la postura oficiosa sostenida desde la ACN de P, defendida por otros propagandistas como Sánchez Bella. Aunque la decepción ante la falta de desarrollo político terminaría afectando a muchos que creyeron en las posibilidades de la vía orgánica.

Tales decepciones, unas calladas y otras explícitas -caso Ruiz-Giménez- serían cada vez más claramente manifestadas. Los propagandistas relacionados con la política lo reflejarían con claridad. El sistema empezaba a deshilacharse, aunque mientras tanto y en las fechas tratadas, la mayoría del grupo político propagandista siguió adoptando mayoritariamente un viejo principio de la casa: la lealtad al régimen constituido buscando su perfeccionamiento y su desarrollo político.

\section{PRINCIPALES OBRAS DE ESOS AÑOS}

Del mismo modo que El Debate había sido el elemento nuclear de la obra de Ángel Herrera, la prohibición ante una posible reaparición trasladó el protagonismo periodístico al conjunto de periódicos de La Editorial Católica. Esta contaba con cinco diarios, que eran Ya de Madrid, Ideal de Granada, Hoy de Badajoz, El Ideal Gallego de La Coruña y La Verdad de Murcia. Los datos correspondientes dentro de este conjunto a las tiradas de prensa diaria de La Editorial Católica -tomando el año 1965- de los tres primeros periódicos eran 130.000 (195.000 los domingos), 20.000 y otros 20.000 ejemplares respectivamente. ${ }^{40}$ En conjunto la prensa de La Editorial Católica venía a suponer aproximadamente un $60 \%$ de las tiradas de diarios vinculados a la Iglesia, y un $12 \%$ del total, contando con una cabecera de primer orden, el diario Ya. Si se compara

\footnotetext{
${ }^{40}$ Los Anuarios de la Prensa de la época son bastante heterogéneos en cuanto a contenido. En ocasiones figuraban las cifras de tirada, pero no siempre. Así por ejemplo, en los diarios de F.E.T. y de las J.O.N.S. no figuraba tal dato, pero no era el único caso. Tampoco de algunos de La Editorial Católica, como por ejemplo El Ideal Gallego o La Verdad de Murcia.
} 
la influencia de $Y a$ con otros diarios madrileños de la época, ha de decirse que las tiradas del madrileño $A B C$ y del diario Madrid eran 186.000 y 68.000 ejemplares respectivamente; es decir, que $Y a$, con sus 130.000 ejemplares, ocupaba un lugar intermedio entre ambos. ${ }^{41}$

En cuanto a la presencia de la Biblioteca de Autores Cristianos, la BAC, también promovida desde La Editorial Católica, cabe decir que en febrero de 1958 Pío XII recibió a la comisión de la editorial que le entregó los ochenta segundos volúmenes de la Biblioteca de Autores Cristianos; Radio Vaticana recordaría que se habían publicado 2.100 .000 ejemplares distribuidos por todo el mundo, un cuarenta y cinco por ciento de ellos en América. En abril de 1961 la BAC ya había editado cuatro millones de ejemplares y doscientos volúmenes. Y el 26 de marzo de 1965, el recién creado cardenal Ángel Herrera Oria, entregó al Sumo Pontífice los doscientos cuarenta volúmenes de la BAC, habiéndose editado 5.600.000 ejemplares. Pablo VI la calificaría como «aristocrática por su contenido y democrática por su difusión», señalando que ningún otro país podía ofrecer un ejemplo semejante, pasando los libros a su biblioteca oficial.

Otra obra que con el tiempo sería la principal de la Asociación, el Centro de Estudios Universitarios, tenía por esas fechas la siguiente evolución en cuanto a su alumnado:

\begin{tabular}{|c|c|c|c|}
\hline Curso & Alumnos & Curso & Alumnos \\
\hline $1951-1952$ & 60 & $1958-1959$ & 398 \\
\hline $1952-1953$ & 56 & $1959-1960$ & 583 \\
\hline $1953-1954$ & 75 & $1960-1961$ & 534 \\
\hline $1954-1955$ & 102 & $1961-1962$ & 560 \\
\hline $1955-1956$ & 115 & $1962-1963$ & 593 \\
\hline $1956-1957$ & 138 & $1963-1964$ & 633 \\
\hline $1957-1958$ & 145 & $1964-1965$ & 650 \\
\hline
\end{tabular}

Las cifras no incorporan ni a los alumnos del curso preuniversitario ni a los opositores. Cabe además observar que los resultados académicos eran superiores a la media, y que se obtuvieron notables éxitos en los resultados de preparación

${ }^{41}$ Ver Cantavella, J. y Serrano, J.F. 2010. Los periódicos de la Editorial Católica: Madrid: Edibesa. Sobre la evolución del principal diario de La Editorial Católica, ver Martín Aguado, J.A. y Vilamor, José R. 2012. Historia del Ya. Sinfonía con final trágico: Madrid: CEU Ediciones. 
de oposiciones a los cuerpos más distinguidos de la administración. El CEU se concibió como un embrión de universidad privada, pues dadas las tradicionales influencias estatistas en la universidad, no era fácil una modificación de estatus. Con setenta y cinco alumnos había iniciado su andadura el CEU en 1933, teniendo como rector a Don Federico Salmón, abogado del Estado -como el propio don Ángel Herrera Oria- futuro ministro de Trabajo de la C.E.D.A. en 1935, cuyos días concluirían trágicamente en noviembre de 1936 en Paracuellos de Jarama. Nada más concluir la guerra volvió el CEU a reiniciar sus actividades en un modesto piso cercano a su antigua sede con sólo veinticinco alumnos. Pese a que desde agosto de 1939 era ministro de Educación Nacional José Ibáñez Martín, un miembro de la ACN de P, no pudo conseguirse otra cosa salvo un régimen de estudios paralelos con cierto grado parcial de convalidaciones. $\mathrm{Ni}$ siquiera durante la época de Ruiz-Giménez como ministro de Educación Nacional se pudo plantear la cuestión de la universidad católica no estatal, aunque el asunto empezaría a tratarse como posibilidad a mediados de la década de los cincuenta. Cuando en 1951 fue inaugurado el Colegio Mayor de San Pablo, obra de imponente arquitectura, el CEU quedaría configurado como su órgano docente. Colegio Mayor que ha sido desde esas fechas un centro de referencia en su ámbito.

Tales obras eran específicas creaciones de la ACN de P, pero los propagandistas tenían también actuaciones en obras cuya gestión se les encomendaba, tal como se ha mencionado con la dirección de Acción Católica hasta 1959 y con Cáritas, donde dejó su impronta Jesús García Valcárcel. O colaboraciones que exigían un importante esfuerzo económico, como el generoso apoyo ofrecido para la adquisición en La Granja del centro de ejercitaciones del Movimiento por un Mundo Mejor, promovido por el jesuita florentino Ricardo Lombardi y apoyado por Pío XII, centro que sería inaugurado en 1956.

Cabe decir, por tanto, que la ACN de P durante el período tratado es uno de los elementos esenciales para la actuación social del catolicismo en muy diversos ámbitos, tal como fue proyectada por su fundador, Don Ángel Ayala SJ y por quien sería su hombre de referencia, Don Ángel Herrera Oria.

\section{FUENTES Y BIBLIOGRAFÍA}

Archivo Fernando María Castiella. Real Academia de la Historia.

Archivo del Ministerio de Asuntos Exteriores. Correspondencia con

Embajada de España ante la Santa Sede.

Archivo Alberto Martín Artajo. Archivo familiar.

Archivo de la Fundación Francisco Franco. 
Boletín de la AC de P. Archivo de la AC de P.

Andrés Gallego, J. 1992. «Entre la religión y la política», en Andrés Gallego (coord.), Historia general de España y América: T. XIX-1,136-137 Madrid: RIALP.

Arboleya, M. 1930. Otra Masonería. El integrismo: Madrid: Cía. Ibero-Americana de Publicaciones.

Arrese, J.L. 1982. Una etapa constituyente. Testimonio de la marginación de la Falange por Franco: Barcelona: Planeta.

Barreiro, C. 2010. Historia de la Asociación Católica de Propagandistas, (19351953): Madrid: CEU Ediciones. Edibesa.

Cantavella, J. y Serrano, J.F. 2010. Los periódicos de la Editorial Católica: Madrid:

Enrique y Tarancón, V. 1996. Confesiones: 151-152 Madrid: PPC.

Fraga Iribarne, M. 1980. Crónica de medio siglo 1931-1982: 135 Barcelona: Planeta.

Gutiérrez García, J.L. 2010. Historia de la Asociación Católica de Propagandistas. (1908-1923): Madrid: CEU Ediciones.

Hermet, G. 1980. Les catholiques dans l'Espagne franquiste: 46-48 Paris: Presses de la Fondation Nationale de Sciences Politiques.

Iribarren, J. 1974. Documentos colectivos del episcopado español. 1870 - 1964 : 267-291 Madrid: BAC.

Laboa, J.M. 1985. El integrismo, un talante limitado y excluyente: Madrid: Narcea.

Larkin, M. 2004. L'Église et l'État en France. 1905: La crise de la séparation: 198200 Paris: Privat.

Lecanuet, É. 1910. L’Église de France sous la Troisième République (1878-1894): XI París: Ancienne Librairie Poussielgue.

López Rodó, L. 1990. Memorias: 748-754 Esplugues de Llobregat: Plaza Janés.

Marquina Barrio, A. 1983. La diplomacia vaticana y la España de Franco: 330 Madrid: CSIC.

Martín Aguado, J.A. y Vilamor, José R. 2012. Historia del Ya. Sinfonía con final trágico: Madrid: CEU Ediciones.

Martín Puerta, A. 2010. Historia de la Asociación Católica de Propagandistas, (1953-1965): Madrid: CEU Ediciones.

Rovan, J. 1964. El catolicismo político en Alemania: 158 Madrid: Instituto de Estudios Políticos.

Sáinz Rodríguez, P. 1981. Un reinado en la sombra: 227-228 Barcelona: Planeta. 
Santamarina, Á. 1977. Joaquín Ruiz-Giménez. Perfil humano y político: Madrid: Editorial Cambio 16.

Silva Muñoz, F. 1993. Memorias Políticas: 91-93 Barcelona: Planeta.

Tusell, J. 1993. Carrero. La eminencia gris del régimen de Franco: 290 Madrid: Temas de hoy. 